\title{
Revisión crítica del marco institucional y legal chileno de ordenamiento territorial: el caso de la zona costera ${ }^{1}$
}

\author{
Belisario Andrade ${ }^{2}$, Federico Arenas $^{2}$ y Rodrigo Guijón ${ }^{2}$
}

\section{RESUMEN}

En el marco de una creciente transformación del espacio costero chileno que deja al descubierto una serie de conflictos de uso y riesgos significativos por incompatibilidad de los mismos, este trabajo busca aportar un panorama general respecto de los diversos organismos públicos competentes para la regulación y gestión del espacio costero, de sus funciones principales o subordinadas y de la interacción entre ellos, así como de los principales defectos que se producen desde el punto de vista del sistema legal, para fines del ordenamiento territorial en general y del ordenamiento costero, en particular. Se identifican los textos legales y reglamentarios considerados relevantes para la regulación del uso del suelo, incluyendo tanto normas directas como indirectas.

Palabras clave: Borde costero, zona costera, planificación territorial, gestión territorial.

\begin{abstract}
The increasing transformations of the Chilean coastal space raise a series of land use conflicts and significant risks caused by incompatibility of such different uses. In that context, this paper delivers an overview of the diversity of public offices in charge of coastal space regulation and management, and the issues associated to it; amongst them, their principal or subordinate functions, interaction between them, as well as the main problems arising from the point of view of the Chilean legal system, generally for purposes of territorial planning, and more specifically for coastal planning. The main legal statutes and decrees considered relevant as land use regulations are identified, including both direct and indirect regulations.
\end{abstract}

Key words: Coastal fringe, coastal zone, physical planning, spatial management.

La revisión de la literatura especializada ha dejado establecido que entre las respuestas más significativas a los procesos de transformación del espacio costero y al manejo de los múltiples conflictos que se dan allí, figuran los esfuerzos implementados en Europa en las décadas de los setenta y ochenta. Ejemplos de ello son un acta para

1 Artículo recibido el 12 de marzo de 2008 y aceptado el 12 de septiembre de 2008. la planificación en áreas costeras, de Noruega en 1971; las bases de una política global de ordenamiento de la zona costera, en Gran Bretaña en 1972 y; desde 1973, en Francia donde se desarrollan diversas aproximaciones para establecer un cuerpo legal operativo, el que se consolida con la

2 Instituto de Geografía, Pontificia Universidad Católica de Chile (Chile).E-mail: bandrade@uc.cl; farenasv@uc.cl; rguijon@uc.cl 
materialización de una ley litoral en 1986 y en y con la creación del conservatorio del litoral. En el mismo período, en Estados Unidos, se establece un acta de manejo de la zona costera, en 1972 (Becet, 1987).

Uno de los enfoques que permite abordar el tema de la coherencia entre las características del medio natural y las actividades que en él se desarrollan corresponde, según Andrade et al. (2000), al conjunto de procedimientos propios del denominado ordenamiento territorial, entendido como la adecuada articulación de la voluntad o los intereses de una comunidad humana con las potencialidades del medio natural. El ordenamiento territorial de la zona costera plantea dificultades particulares, ya que ella corresponde a una entidad espacial con características propias, vinculadas a la interacción de procesos situados en la interface entre la geósfera, atmósfera e hidrósfera, condición que le otorga características ambientales de fragilidad y vulnerabilidad, y por otra parte, porque por naturaleza esta zona constituye un espacio muy atractivo para diversas actividades humanas (urbanas, industriales, turísticas, de transporte, agrícolas, acuícolas, pesqueras y otras actividades extractivas), lo que produce la concurrencia de múltiples usos y con frecuencia la generación de conflictos territoriales.

Los actuales procedimientos aplicados en Europa corresponden a un modelo integrado de gestión de las zonas costeras que involucra un conjunto amplio de formulaciones de carácter estratégico tales como análisis, definición de temas claves, definición de objetivos operativos y estratégicos, definiciones de diagnósticos, metas, para finalmente alcanzar el nivel de un plan de acción (Barragán et al., 2008). Este trabajo se centra solo en algunos de los aspectos considerados a nivel de diagnóstico estratégico en el modelo antes citado, esto es, el análisis de la normativa, de las competencias y de las instituciones.

Una de las hipótesis centrales de la línea de investigación de los autores de este trabajo se asocia al hecho que las actividades económicas emergentes modifican de manera preferencial espacios no urbanos, los que dada la poca "resonancia geográfica" 3 y las debilidades institucionales y legales vigentes en el país, quedan "desregulados" y sometidos al desarrollo de actividades humanas, que si se realizan de manera indiscriminada (sobre la realidad espacial ambientalmente diferenciada), impondrán cambios estructurales muy significativos y con efectos probablemente irreversibles desde el punto de vista de la sustentabilidad ${ }^{4}$ de dichos espacios (Andrade et al., 2000).

Por las razones expuestas, las zonas costeras representan un espacio de interés para la Geografía, no solo por el hecho de ser espacios frágiles y por corresponder a zonas fuertemente presionadas debido a su localización privilegiada para diversas actividades humanas, incluido el proceso de masificación de segundas residencias, sino también debido a la función que estos espacios tienen asignada en un esquema de creciente integración económica planetaria, en donde las costas representan la zona de contacto con el mundo exterior. En el caso de Chile, la zona costera en general y la costa del denominado Chile central en particular, ha sido y es objeto de una presión antrópica creciente. Las características geográficas de la zona costera chilena, las crecientes actividades humanas y su impacto en ella y el estado de la gestión, han sido descritas y analizadas en Barragán et al. (2004; 2005).

En una primera parte de este trabajo se expone una reflexión sobre el significado de los conceptos de planificación del territorio y gestión territorial, de normas directas e indirectas de ordenamiento territorial, de organismos centralizados y descentralizados, y borde costero y zona costera. En la segunda parte se intenta aclarar las múltiples interacciones, superposiciones y con-

3 Concepto acuñado por Francisco Sabatini en discusiones desarrolladas en el marco del proyecto "Las relaciones entre actores Institucionales y territorios: estudio comparativo entre Francia y Chile" (Proyecto ECOS-CONICYT N C99H02), que se refiere a la persistencia en el espacio de las huellas de decisiones pasadas, que por su profundidad condicionan su desarrollo futuro.

4 La sustentabilidad entendida en el sentido que le da el "Informe Brundtland" (Comisión Mundial del Medio Ambiente y del Desarrollo (CMMAD), 1987). 
flictos existentes entre los diversos componentes de la estructura orgánica a cargo de la gestión y regulación del espacio costero. En la tercera parte se analizan las normativas relevantes para la zona costera en general y en la cuarta parte se evalúan los instrumentos de planificación y de gestión territorial existentes.

\section{Antecedentes generales}

El estudio y análisis de la institucionalidad y la normativa existente en Chile resulta un método adecuado para la comprensión del funcionamiento y el papel de los sistemas jurídico e institucional en el ordenamiento territorial costero. En este mismo sentido, ello permite diagnosticar las virtudes, defectos y eficacia de los sistemas mencionados, como constituyentes de la estructura de ordenamiento territorial.

Otro aspecto básico consiste en dilucidar qué organismos tienen competencia para intervenir en materia territorial y cuáles son sus respectivas funciones y atribuciones, así como su grado de coordinación o coherencia en la operación con otros organismos públicos y privados relevantes.

En este trabajo se entenderá por normas de ordenamiento territorial a aquellas normas jurídicas relativas a la organización del territorio de acuerdo con los diferentes usos posibles del suelo, haciendo algunas distinciones relevantes, por una parte, entre ordenamiento, planificación y gestión territorial, y entre normas directas e indirectas de ordenamiento territorial, por otra.

De acuerdo con Pujadas y Font (1998) y al diccionario multilingüe de Evert (2001), ordenamiento u ordenación territorial se refiere a los objetivos y directrices, o sea, al desarrollo de las líneas principales de planificación y los instrumentos que sirven para ello. En tanto, la planificación territorial implica el desarrollo de planes y medidas para la implementación de aquellos objetivos o directrices que definen un modelo territorial futuro. En consecuencia, desde el punto de vista de las normas jurídicas que se dictan, teniendo como objetivo el ordenamiento o la planificación territorial, se habla respectivamente de normas (generales) de ordena- miento territorial y de instrumentos de planificación territorial (IPT).

Cuando en virtud de las normas generales de ordenamiento o de los instrumentos de planificación territorial, la autoridad administrativa dicta, modifica o revoca permisos específicos para uso del suelo en un lugar determinado, o decreta sanciones por usos o actividades indebidas, no se trata ya de planificación, sino de administración o gestión del territorio, por lo que desde nuestro punto de vista es más apropiado hablar de instrumentos de gestión territorial (IGT).

Un ejemplo claro de lo anterior son las normas e instrumentos para el ordenamiento urbano chileno: las normas generales están constituidas principalmente por la Ley General y la Ordenanza General de Urbanismo y Construcciones, mientras que los instrumentos de planificación que se dictan a partir de ellas son los planes regionales de desarrollo urbano ${ }^{5}$, los planes reguladores intercomunales y comunales, los límites urbanos y los planes seccionales; y los instrumentos de gestión están dados por los permisos de construcción, las recepciones de obras, las multas y sanciones que aplican las municipalidades caso a caso.

Adicionalmente, también hay normas generales de ordenamiento territorial, las que sin contemplar instrumentos de planificación regulan directamente la gestión del territorio a través de ciertos organismos. En el caso específico del ordenamiento territorial costero, la Ley de Concesiones Marítimas, sin establecer una planificación para el otorgamiento de tales concesiones, regula la forma y requisitos para dicho otorgamiento mediante decreto supremo emitido por la Subsecretaría de Marina.

Las normas de ordenamiento territorial admiten también una subclasificación entre normas directas e indirectas. Las primeras

\footnotetext{
5 Actualmente se trabaja en el Estado chileno en el traspaso de la responsabilidad de los Planes Regionales de Desarrollo Urbano (PRDU), desde el Ministerio de Vivienda y Urbanismo a los Gobiernos Regionales, específicamente a su nueva División de Planificación Regional, transformándolos además en Planes Regionales de Ordenamiento Territorial (PROT).
} 
tienen como propósito principal la regulación del uso del suelo. El único caso en Chile es el de la planificación urbana, a través de las normas e instrumentos señalados precedentemente. Las segundas tocan la regulación del uso del suelo indirectamente, pero de manera fundamental a raíz de las materias que regulan, las que aunque no se refieren directamente al uso del suelo, inciden finalmente en él. Estas normas indirectas pueden ser a su vez de dos tipos: orgánicas, cuando regulan la organización, atribuciones y funcionamiento de los diversos organismos públicos encargados de la planificación y gestión del territorio, tal como las leyes orgánicas de los diferentes ministerios competentes, y sectoriales, cuando regulan los requisitos para la instalación y el ejercicio de actividades específicas sobre el suelo o la explotación de este por parte de personas determinadas, como es el caso del Código de Minería, el Código de Aguas, la Ley de Navegación, la Ley General de Pesca y Acuicultura, el Reglamento de Deportes Náuticos, entre muchas otras.

La institucionalidad que existe para la creación y ejecución de IPT e IGT, así como para la administración pública en general, está constituida por servicios públicos que se clasifican en centralizados, los que dependen directamente de la administración del Estado (ministerios y servicios públicos generales), y descentralizados, los que legalmente constituyen personas jurídicas distintas del Estado y cuentan con patrimonio propio, sin perjuicio de lo cual sus políticas generales son definidas también por el poder central. Los organismos centralizados, para llevar a cabo sus funciones en todo el territorio nacional se subdividen o desconcentran a distintas escalas (escala regional, provincial y comunal), denominando a tales reparticiones regionales, provinciales o comunales, servicios desconcentrados.

Un último aspecto relevante se refiere al ámbito territorial en que se aplica el ordenamiento. En Chile se manejan dos conceptos similares, pero con significados muy diferentes: el borde costero y la zona costera. El borde costero es un concepto legal, utilizado principalmente en la Política Nacional de Uso del Borde Costero del Litoral de la República (D.S. 475, de 1994, del Ministe- rio de Defensa Nacional), que es el que se utiliza actualmente para efectos de la gestión del territorio costero, entendiéndose por borde costero, de acuerdo con dicha política, a "aquella franja del territorio que comprende los terrenos de playa fiscales, la playa, las bahías, golfos, estrechos y canales interiores, y el mar territorial de la República" -todos estos términos se encuentran también definidos por ley-, y que "conforma una unidad geográfica y física de especial importancia para el desarrollo integral y armónico del país".

En la práctica, el ámbito territorial en el cual la norma tiene aplicación es sumamente reducido ya que está limitado a los denominados terrenos de playa de mar, es decir, aquellos terrenos colindantes al estrán (Figura $N^{\circ} 1$ ), los que cuando comprenden un predio fiscal, alcanzan solo ochenta metros de ancho. Cuando la playa de mar se encuentra frente a predios privados no existe espacio para la planificación terrestre.

La zona costera, en cambio, es un concepto más bien científico-técnico, que sin establecer un área claramente delimitada se refiere a todo el ámbito de interacción física, biológica y también antrópica entre los ambientes terrestre y marino. Para Andrade y Castro (1987) la delimitación de la zona costera se puede realizar a partir de diversos criterios, en función de la disciplina involucrada en su estudio; sin embargo, hay un acuerdo general en considerarla como un espacio geográfico de extensión variable, situado en el contacto entre la litosfera, la hidrosfera y la atmosfera, lo que le otorga características únicas tanto de riqueza como de fragilidad y complejidad. Andrade (2001) agrega que ella corresponde a "una franja de ancho variable, donde interactúan el mar, la tierra y la atmósfera, determinando un ambiente de interfase en el que se establecen condiciones de equilibrio precario y ocurren procesos dinámicos intensos que le confieren características únicas de fragilidad ambiental". Castro y Morales (2006) suman a ello que en dicha franja existe un contacto interactivo entre la naturaleza y las actividades humanas. En consecuencia, en este artículo no se puede delimitar la zona costera dado que ella no está reconocida como tal en los instrumentos y normas existentes. 


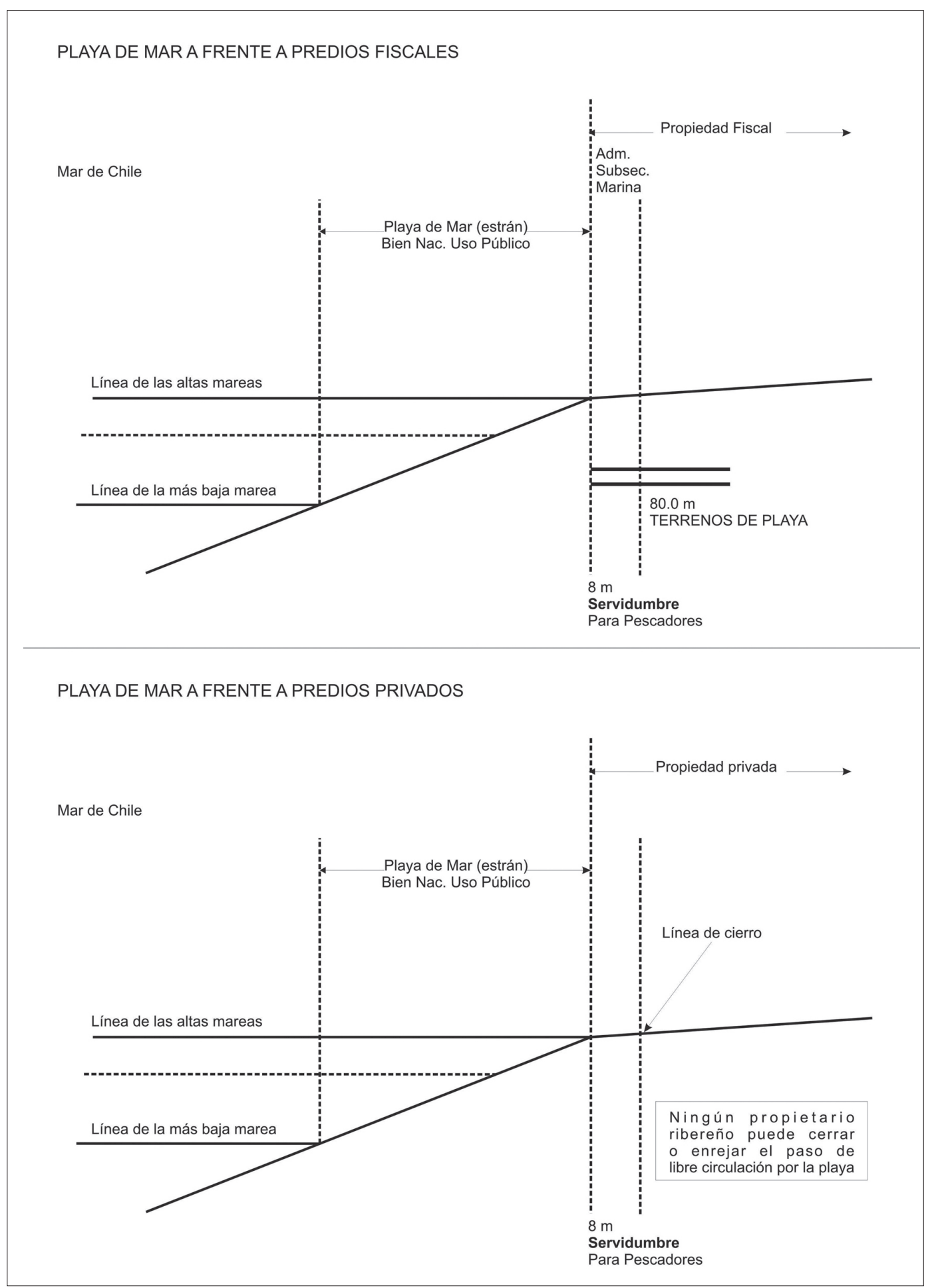

Fuente: Adaptado de Ministerio de Bienes Nacionales de Chile (1997). 
Esta discusión sobre estos diferentes elementos conceptuales muestra la dificultad que existe para un ordenamiento territorial efectivo en el ámbito costero: no solo se trata de un territorio de difícil delimitación y que, por lo tanto, requiere de una aplicación "criteriosa" de las normas que regulan el uso del suelo, sino además, la gran cantidad de normas de ordenamiento territorial y los diversos organismos que tienen competencia para la planificación y gestión del territorio, de acuerdo con dichas normas, plantea un panorama complejo que hace difícil integrar la planificación y gestión, para que el ordenamiento costero considere adecuadamente la fragilidad ambiental característica del espacio.

\section{La institucionalidad chilena vigente para el ordenamiento territorial del borde costero}

Los textos legales y reglamentarios para el ordenamiento del borde costero contemplan distintas definiciones a partir de las cuales se desprende el ámbito territorial de aplicación ${ }^{6}$ de las mismas normas. De acuerdo con ellas, los organismos competentes para intervenir en la planificación o gestión de dicho territorio solo actúan válidamente en él, y no tienen atribuciones para extender sus planes e instrumentos más allá de dicho territorio (sin perjuicio de que puedan actuar coordinadamente con los organismos competentes en territorios aledaños o vecinos $)^{7}$.

\footnotetext{
6 El "ámbito territorial de aplicación" de una norma jurídica se refiere a la extensión de territorio en la cual dicha norma surte sus efectos, y puede consistir en el territorio nacional, el de una región, provincia o comuna, o aun en un área especialmente definida por la misma norma.

7 Los conceptos legales considerados relevantes para la definición del borde costero son: las aguas interiores, el borde costero, el fondo de mar, río o lago, la franja de playa a cuyo uso tienen derecho los pescadores, la línea de base normal, la línea de playa o línea de más altas mareas, el mar territorial y en menor medida el mar presencial, la playa de mar, la porción de agua, el terreno de playa y la Zona de Protección Costera. Las normas jurídicas de las cuales se definió dicho ámbito territorial del borde costero son principalmente las siguientes (entre paréntesis se indica el instrumento legal en que se encuentra establecida la norma):
}

Como se señaló precedentemente, se entiende por borde costero del litoral aquella franja del territorio que comprende los terrenos de playa fiscales situados en el litoral, la playa, las bahías, golfos, estrechos y canales interiores, y el mar territorial de la República, que se encuentran sujetos al control, fiscalización y supervigilancia del Ministerio de Defensa Nacional, Subsecretaría de Marina. En consecuencia, es en el borde costero donde se aplican de manera fundamental las normas de ordenamiento y gestión contempladas en el ordenamiento jurídico chileno para el litoral.

Con respecto a los organismos competentes para llevar a cabo el ordenamiento y gestión, las diferentes normas consideradas establecen una serie de entidades públicas con atribuciones de mayor o menor relevancia para ello. Basta tener en cuenta el ministerio de origen de las distintas normas mencionadas en la nota al pie $\mathrm{N}^{\circ} 7$ para comprender que al menos esos ministerios y algunos de sus organismos subordinados tie-

- Ia Ley de Concesiones Marítimas (DFL 340, de 1969, del Ministerio de Hacienda) y su Reglamento (DS 2, de 2005, del Ministerio de Defensa Nacional);

- el Reglamento para el Control de la Contaminación Acuática (DS 1, de 1992, del Ministerio de Defensa Nacional);

- Ia Ley General de Pesca y Acuicultura (DS 430, de 1991, del Ministerio de Economía, Fomento y Reconstrucción);

- el Código Civil (DFL 1, de 2000 del Ministerio de Justicia), que contiene las primeras normas en que se definen los conceptos de playa de mar y de mar territorial, entre otros;

- el Reglamento General de Orden, Seguridad y Disciplina en las Naves y Litoral de la República (antiguo Reglamento General de Policía Marítima, Fluvial y Lacustre; DS 1.340 bis, de 1941, del Ministerio de Defensa Nacional)

- el Reglamento de Deportes Náuticos (DS 87, de 1997, del Ministerio de Defensa Nacional);

- Ia Ordenanza General de la Ley General de Urbanismo y Construcciones (DS 47, de 1992, del Ministerio de Vivienda y Urbanismo);

- el Reglamento de Concesiones y Autorizaciones de Acuicultura (DS 290, de 1993, del Ministerio de Economía, Fomento y Reconstrucción);

- Ia Política Nacional de Uso del Borde Costero del Litoral de la República (DS 475, de 1994, del Ministerio de Defensa Nacional); y

- la ley que regulariza situación de ocupaciones irregulares en borde costero de sectores que indica (Ley 20.062). 
nen competencia para regular o administrar el territorio costero a partir de su quehacer sectorial. Así sucede con la Subsecretaría de Marina dependiente del Ministerio de Defensa Nacional, para efectos de las concesiones marítimas; con la Subsecretaría de Pesca, dependiente del Ministerio de Economía, Fomento y Reconstrucción, para efectos de la gestión y control de las actividades pesqueras y acuícolas; o con las Municipalidades, sujetas a la fiscalización de las Secretarías Regionales Ministeriales del Ministerio de Vivienda y Urbanismo, en lo que se refiere a la planificación urbana de áreas costeras.

En síntesis, los organismos con competencia para la regulación y gestión del borde costero son:

- La Dirección General del Territorio Marítimo y de Marina Mercante (DIRECTEMAR), y la autoridad marítima dependiente de ella y también de la Armada de Chile ${ }^{8}$;

- La Armada de Chile;

- Carabineros de Chile;

- La Subsecretaría de Pesca, dependiente del Ministerio de Economía, Fomento y Reconstrucción;

- El Servicio Nacional de Pesca;

- La Dirección de Obras Portuarias, dependiente del Ministerio de Obras Públicas;

- El Ministerio de Bienes Nacionales;

- Las Municipalidades;
- La Subsecretaría de Marina, dependiente del Ministerio de Defensa Nacional; y

- La Comisión Nacional de Uso del Borde Costero.

En el ejercicio de sus funciones más relevantes, estos organismos se relacionan entre sí en la forma que se reproduce en el Cuadro $N^{\circ} 1$ (para observar todas las normas de ordenamiento territorial analizadas, ver Anexo $\mathrm{N}^{\circ}$ 1).

La institución básica encargada de la planificación y gestión del borde costero es la Comisión Nacional de Uso del Borde Costero (CNUBC), creada en la Política Nacional de Uso del Borde Costero del Litoral de la República (D.S. 475, de 1994, del Ministerio de Defensa Nacional), compuesta a su vez por representantes de diferentes organismos públicos relevantes, entre los cuales se consideran no solamente aquellos relativos al territorio marítimo, sino también ciertas autoridades sectoriales como los ministerios de Planificación, de Obras Públicas, de Vivienda y Urbanismo, el Servicio Nacional de Turismo o la Comisión Nacional de Medio Ambiente (Cuadro $N^{\circ} 2$ ). Se echa de menos, sin embargo, la participación de los ministerios de Agricultura y de Minería y Energía, los cuales desde el punto de vista de una gestión integral de la zona costera -en la forma en que se le definió más arriba-, tienen roles muy importantes en todas aquellas áreas en que las actividades de su rubro interfieren o coincidan con el ambiente costero.
8 La autoridad marítima se encuentra definida básicamente en el Reglamento General de Orden, Seguridad y Disciplina en las Naves y Litoral de la República (antiguo Reglamento General de Policía Marítima, Fluvial y Lacustre; DS 1.340 bis, de 1941, del Ministerio de Defensa Nacional), y sus atribuciones principales se establecen en la Ley Orgánica de la Dirección de Territorio Marítimo y Marina Mercante (DFL 292, de 1953, del Ministerio de Hacienda). Se entiende como autoridades marítimas: al Director General de Territorio Marítimo y de Marina Mercante -quien es la autoridad superior-, los gobernadores marítimos y los subdelegados marítimos (estos dos últimos se denominan genéricamente capitanes de puerto). Los cónsules chilenos, en los casos que la ley determine, y los alcaldes de mar se consideran autoridades marítimas para efectos del ejercicio de las atribuciones específicas que les asigne el Director General. 


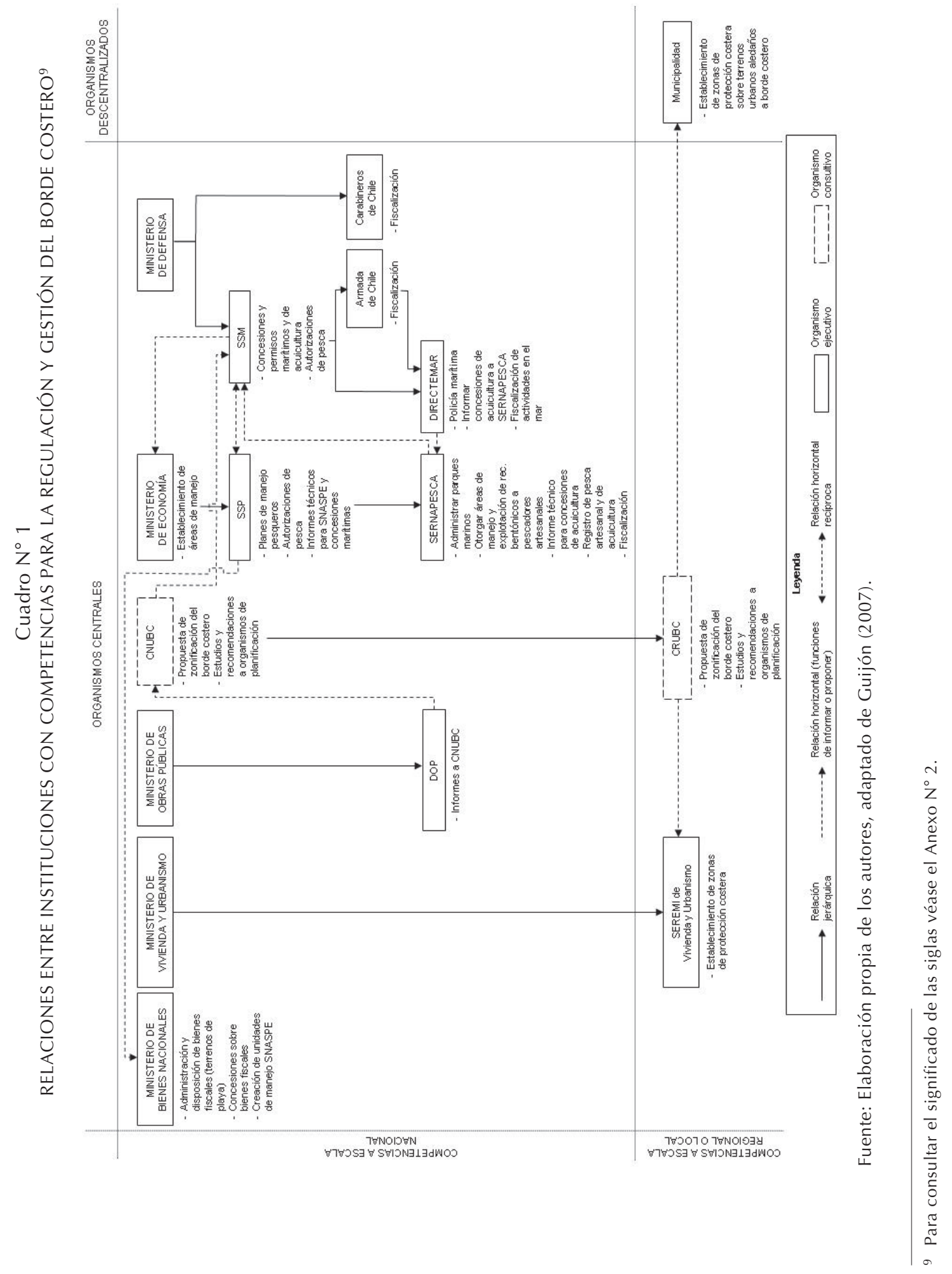


Integrantes de la CNUBC (art. 3º, D.S. 475, 1994, Ministerio de Defensa):

1. Ministro de Defensa Nacional (preside)

2. Subsecretario de Marina

3. Representante de la Subsecretaría de Desarrollo Regional y Administrativo del Ministerio del Interior

4. Representante de la Subsecretaría de Pesca del Ministerio de Economía, Fomento y Reconstrucción

5. Representante del Ministerio de Planificación y Cooperación

6. Representante del Ministerio de Obras Públicas

7. Representante del Ministerio de Vivienda y Urbanismo

8. Representante del Ministerio de Transportes y Telecomunicaciones

9. Representante del Ministerio de Bienes Nacionales

10. Representante de la Armada de Chile

11. Representante del Servicio Nacional de Turismo

12. Representante de la Comisión Nacional del Medio Ambiente

Fuente: Elaboración propia de los autores, a partir de Guijón (2007).

Esto pone de manifiesto que en el borde costero, espacio más o menos restringido, pueden confrontarse intereses de sectores productivos marinos, de conservación del ámbito marítimo (regulados en la Ley de Pesca y Acuicultura) e intereses de asentamientos urbanos, pero sin tomar en cuenta en toda su extensión la influencia que las actividades agrícolas o mineras podrían tener sobre las áreas costeras aledañas, tanto marítimas como terrestres.

Las atribuciones de la CNUBC, conforme a la Política Nacional, son fundamentalmente consultivas, tal como se lee en el art. $2^{\circ}$ del D.S. 475, recogido en el Cuadro $N^{\circ} 3$.

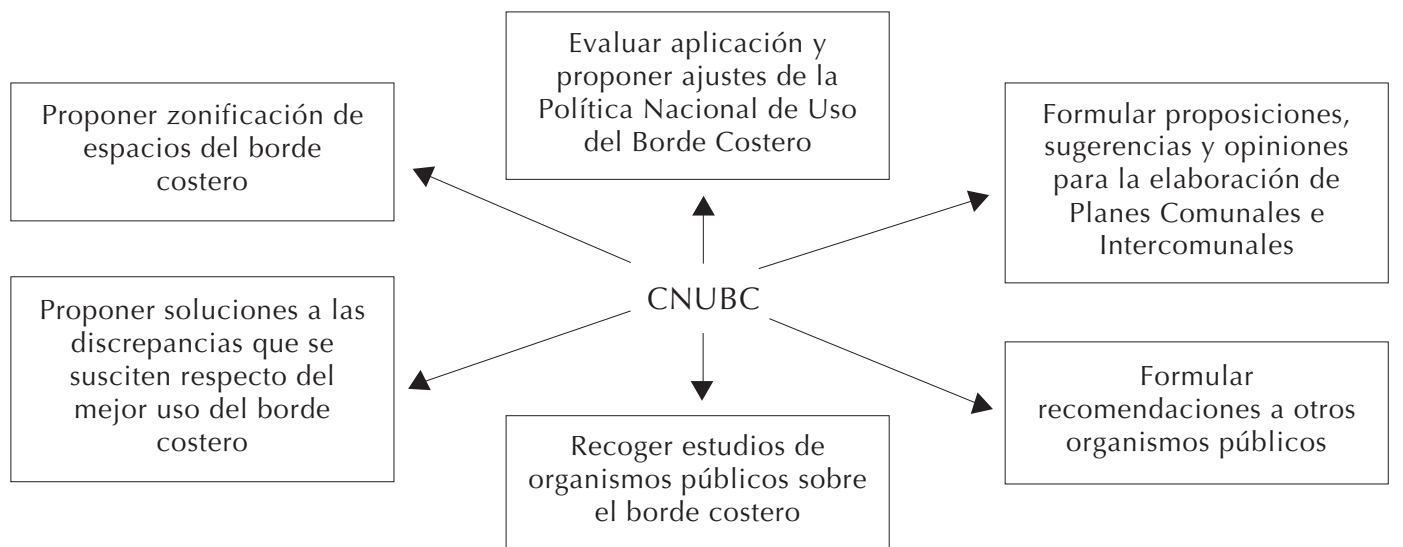

Fuente: Guijón (2007). 
Una de las atribuciones señaladas es la de aprobar propuestas de zonificación del borde costero, lo que podría considerarse una forma importante de planificación territorial costera. Sin embargo, solo se trata de propuestas de zonificación a las cuales los organismos gestores del borde costero resuelven facultativamente acogerse, sin tener un efecto vinculante directo para todos los usuarios del borde costero. En consecuencia, corresponden a propuestas de planificación sectorial, que eventualmente pueden ser aplicadas por los organismos encargados de regular y controlar las actividades productivas de pesca y acuicultura, de turismo y de asentamientos urbanos en el litoral mismo, pero que no se insertan en un contexto general de ordenamiento de los espacios terrestres y marítimos.

Por lo anterior, el esfuerzo de ordenamiento realizado por la CNUBC tiene un alcance limitado para efectos de la regulación de todas las actividades que tienen impacto en la zona costera, dado su nulo efecto vinculante y su escasa extensión territorial, al referirse exclusivamente al borde costero, alcanza solamente a una parte de la zona costera.

Del mismo modo, el establecimiento de una Política Nacional de Uso del Borde Costero por medio de decreto supremo, si bien importante como primera iniciativa para regular el espacio costero, es limitado desde el punto de vista de su estabilidad legal, ya que puede quedar sometido a vaivenes políticos del gobierno de turno más que a la voluntad política expresada a través del Poder Legislativo.

Existen otros defectos puntuales en la aplicación de ciertas normas de ordenamiento territorial que dejan también en evidencia la gran dificultad existente en Chile para establecer un sistema de ordenamiento territorial, en particular para la zona costera. Un caso fundamental en este sentido es el del acceso público al litoral. De acuerdo con lo señalado precedentemente, las playas y los terrenos de playa, entre otros, son bienes nacionales de uso público, lo que conlleva el derecho de todos los habitantes de la República para hacer uso de ellos, con la obligación correlativa de respetar y preser- var la naturaleza de estos bienes y haciéndose responsables frente al Estado, como encargado de su gestión, de los daños que se puedan causar en ellos. Sin embargo, en la medida en que no está regulado el acceso público a todos los bienes nacionales de uso público que conforman el borde costero, y que hay zonas costeras en que dicho acceso público simplemente no existe, resulta sumamente difícil controlar la conservación ambiental de esas áreas y evitar su incorrecta utilización.

En numerosas ocasiones, las propiedades privadas colindantes con el borde costero en la práctica generan playas privadas. Esta condición de hecho, dificulta el desarrollo de investigación científica acerca de las condiciones naturales del litoral y el control de los daños que puedan estar ocurriendo. En definitiva, la falta de una política nacional para regular el problema va en desmedro directo del conocimiento y la conservación de ciertas áreas de la zona costera que quedan desprotegidas.

Un ejemplo de lo anterior es la norma del art. 13 del D.L. 1.939, que regula la adquisición, administración y disposición de los bienes del Estado. Dicho artículo establece que los propietarios de terrenos colindantes con playas de mar, ríos o lagos deben facilitar el acceso gratuito a estos, con fines turísticos y de pesca, cuando no existen otras vías al efecto; y regula la forma en que el intendente regional debe fijar las vías de acceso a través de los terrenos privados, en su caso. Sin embargo, esta disposición legal no tiene actualmente aplicación práctica y resulta para muchos inconstitucional. Más allá del debate jurídico que se puede desarrollar $^{10}$, en el hecho no existe una solución

\footnotetext{
10 De hecho, parte de este debate se desarrolló a través de una acción interpuesta en 1996 ante el Tribunal Constitucional por un grupo de parlamentarios en contra de un decreto supremo que pretendió regular la forma en que el intendente regional debía ejercer sus atribuciones conforme al art. 13 del D.L. 1.939. La acción se fundaba, entre otros argumentos, en la inconstitucionalidad del decreto supremo, por atentar contra la garantía del derecho de propiedad que dispone el art. 19, $\mathrm{n}^{\circ}$ 24, de la Constitución Política de la República, conforme a la cual el Estado solo puede disponer de terrenos particulares previa expropiación de
} 
legal al problema del acceso al borde costero que no sea la expropiación por ley que se encuentra establecida en la Constitución, la cual tampoco resulta viable y desemboca a su vez en la indefensión del borde costero. Los fines de conservación, investigación, producción, recreación y uso sustentable de los bienes nacionales de uso público costeros, en general, no tienen prioridad en las decisiones públicas, aun menos por la vía de la expropiación, y los propietarios particulares prefieren muchas veces mantener el estado de cosas para evitar intromisiones legítimas o ilegítimas en sus actividades.

Un problema distinto se produce por el roce entre competencias de los organismos encargados de la gestión y/o planificación del borde costero y territorio terrestre colindante. En el primero tienen atribuciones los organismos ya mencionados, fundamentalmente la autoridad marítima, mientras que en el segundo son responsables principalmente las municipalidades y los servicios públicos desconcentrados del Estado. No obstante, el límite físico entre los ámbitos territoriales de unos y otros, definidos por ley, muchas veces es difícil de determinar en terreno; o se ve alterado por variaciones morfológicas de playas, dunas u otros ambientes costeros a causa de su dinámica natural característica; o incluso en ocasiones, los particulares extienden los límites de sus predios o interferir con sus actividades productivas más allá del límite colindante con los bienes nacionales de uso público costeros.

En el caso anterior se hace necesaria una estrecha colaboración y coordinación, entre los organismos competentes en el ámbito terrestre y en el ámbito marino. La adecuada

ellos a través de una ley. En definitiva, el Tribunal Constitucional acogió la acción declarando inconstitucional el decreto supremo en cuestión, pero sin pronunciarse sobre la constitucionalidad del art. 13 mismo, contenido en el D.L. 1.939 (Sentencia de 02.12.1996 del Tribunal Constitucional, rol No 245 y 246 (acumulados); requerimientos formulados por diversos senadores y diputados para que el Tribunal resuelva la constitucionalidad del Decreto Supremo $N^{\circ} 1^{\circ}$, de 10 de enero de 1996, del Ministerio de Bienes Nacionales, publicado en el Diario Oficial de 6 de agosto del mismo año, de acuerdo al artículo 82, №5, de la Constitución Política de la República. gestión pasa, precisamente, por definir cuál organismo debe encargarse del control y la sanción de las transgresiones a los límites físicos o utilización indebida de bienes nacionales de uso público costero, mediante la coordinación entre organismos del borde costero y organismos del ámbito terrestre, para definir exactamente hasta dónde llegan las atribuciones de cada uno.

Existe una respuesta a lo anterior, en el caso de límites entre zonas urbanas costeras y bienes nacionales de uso público costero, en la Ordenanza General de Urbanismo y Construcciones (D.S. 47, de 1992, del Ministerio de Vivienda y Urbanismo). La declaración de Zonas de Protección Costera en el respectivo plan regulador comunal o en un plan regulador intercomunal permite establecer áreas con actividades de bajo impacto para el ambiente natural costero, que operan por lo tanto como zonas de amortiguación entre las actividades intensivas de los centros urbanos y los intereses productivos o de conservación que puede haber sobre los bienes nacionales de uso público costeros.

\section{Normativas relevantes para la zona costera en general}

Además de la normativa dictada para el ámbito costero en particular (incluyéndose en esta también aquellas normas relativas a actividades de pesca, acuicultura, policía marítima y otras aplicables hasta más allá del límite máximo del mar territorial), el ordenamiento jurídico chileno contiene un gran número de normas aplicables en todo el territorio nacional y, por lo tanto, por extensión también en la zona costera. En la medida en que estas normas inciden o incluso determinan los usos posibles del suelo, se les puede considerar normas directas o indirectas de ordenamiento territorial. El Cuadro $N^{\circ} 3$ contiene todas las normas directas e indirectas analizadas en este trabajo.

La normativa indirecta, sea orgánica o sectorial, es la más profusa y la que representa mayor complejidad de aplicación desde el punto de vista del ordenamiento territorial, precisamente a causa de la cantidad de textos normativos que se pueden incluir 
en este grupo. Si se considera la gran diversidad de actividades, organismos y funciones contenidas en las distintas regulaciones sectoriales, se produce un mosaico de normas cuya aplicación simultánea y coordinada sobre el espacio físico representa múltiples desafíos para las autoridades encargadas del aspecto territorial.

Un caso particular de normativa "sectorial", desde el punto de vista del ordenamiento territorial, es el de la regulación ambiental ${ }^{11}$, a la que se encuentran sometidas las distintas actividades y sectores productivos en el espacio geográfico. Se trata de una normativa transversal para toda actividad o proyecto, la que se encuentra más desarroIlada que la normativa propiamente territorial, a pesar de que el territorio es un tema "transversal", su manejo y planificación se desprende casi exclusivamente de las diversas regulaciones sectoriales.

Las normas ambientales pueden considerarse como normativa territorial indirecta, ya que estas actúan a través de la exigencia de requisitos asociados a los distintos usos del suelo, mediante una suma de requisitos sectoriales. Sin embargo, desde el punto de vista espacial, es la normativa territorial la que debe considerarse como una regulación más, para los efectos de los permisos 'sectoriales', tal como lo exige la normativa ambiental. En consecuencia, esta dualidad entre lo ambiental y lo territorial no obliga a cursos de acción separados para uno y otro ámbito. Al contrario, ambas materias se relacionan constantemente y tienen como elemento común su "transversalidad". Ello resulta un factor importante de considerar para el establecimiento de competencias y procedi-

\footnotetext{
11 Entre las normas ambientales aquí referidas se consideran principalmente la Ley 19.300, sobre Bases Generales del Medio Ambiente, y los distintos reglamentos dictados a partir de ella: del Sistema de Evaluación de Impacto Ambiental (D.S. 95, de 2001, del Ministerio Secretaría General de la Presidencia), para la dictación de normas de calidad ambiental y de emisión (D.S. 93, de 1995, del mismo Ministerio), el que fija el procedimiento y etapas para establecer planes de prevención y descontaminación (D.S. 94, de 1995, del mismo Ministerio).
}

mientos eficientes para la planificación y gestión tanto ambiental como territorial.

\section{Evaluación general de IPT e IGT previstos para la zona costera}

De las normas señaladas en el Cuadro $N^{\circ} 3$, no todas establecen o se refieren directamente a instrumentos para la planificación o la gestión del territorio. Muchas de las normas indirectas orgánicas se refieren simplemente a las funciones y atribuciones de carácter territorial de los organismos. Las normas sectoriales, en tanto, regulan el establecimiento y desarrollo de actividades productivas, de conservación u otras. En la medida en que ello requiere de permisos administrativos de las respectivas autoridades, o incluso la planificación de dicha actividad por parte de la misma autoridad, los instrumentos sectoriales correspondientes pueden entenderse como IPT o IGT en cuanto regulan el desarrollo de la actividad sectorial sobre un territorio concreto. Por último existen también las normas directas, que establecen propiamente IPT e IGT, específicamente en el ámbito urbano.

De acuerdo con lo anterior, las normas indirectas de ordenamiento territorial que contemplan IPT son principalmente las siguientes:

a) La Ley 17.288 , sobre Monumentos $\mathrm{Na}$ cionales (art. 6, $\mathrm{n}^{\circ} 3$ ): establece la elaboración de proyectos y normas para la restauración, reparación, conservación y señalización de monumentos nacionales;

b) El Decreto Ley 1.224, que crea el Servicio Nacional de Turismo (arts. 2 y 11): señala el desarrollo de una Política Nacional de Turismo y de planes, programas y proyectos regionales de desarrollo turístico a cargo de las direcciones regionales de SERNATUR, así como la declaración de Zonas y Centros de Interés Turístico;

c) El Decreto con Fuerza de Ley 1.122, de 1981, del Ministerio de Justicia, que contiene el Código de Aguas (art. 299): dispone la planificación para el desarrollo del recurso hídrico; 
d) El Decreto Supremo 430, de 1991, del Ministerio de Economía, Fomento y Reconstrucción, que fija el texto refundido, coordinado y sistematizado de la Ley $\mathrm{N}^{\circ}$ 18.892, de 1989, y sus modificaciones, Ley General de Pesca y Acuicultura (arts. 2, 8 a 10, y 67): dispone el establecimiento de planes de manejo por unidad de pesquería por parte de la Subsecretaría de Pesca, y la determinación de áreas apropiadas para la acuicultura por parte del Ministerio de Defensa Nacional; y

e) La Ley 19.253, que establece normas sobre protección, fomento y desarrollo de los indígenas, y crea la Corporación Nacional de Desarrollo Indígena (arts. 27 y 39 , letra f): establece la planificación y solicitud de declaración de Áreas de Desarrollo Indígena por parte de la CONADI.

Por su parte, las mismas normas anteriores y otras más establecen también IGT. Entre ellas se pueden mencionar las siguientes:

- Decreto Supremo 4.363, 1931, Tierras y Colonización, que aprueba texto definitivo de la Ley de Bosques;

- Decreto Supremo 2.374, de 1937, del Ministerio de Tierras y Colonización, que establece la reglamentación de explotación de bosques en hoyas hidrográficas declaradas forestales;

- Decreto Supremo 1.340 bis, de 1941, del Ministerio de Defensa Nacional, que deroga el Decreto No 211 de 1924, que aprobó el Reglamento de Policía Marítima y aprueba el Reglamento General de Policía Marítima, Fluvial y Lacustre (actual Reglamento General de Orden, Seguridad y Disciplina en las Naves y Litoral de la República);

- Decreto con Fuerza de Ley 340, de 1969, del Ministerio de Hacienda, Ley de Concesiones Marítimas;

- Ley 16.282, que fija disposiciones para casos de sismos o catástrofes, establece normas para la reconstrucción de la zona afectada por el sismo de 28 de marzo de 1965 y modifica la Ley $N^{\circ} 16.250$;
- Decreto con Fuerza de Ley 725, de 1967, del Ministerio de Salud, que establece el Código Sanitario;

- Decreto Ley 1.939, que fija normas sobre adquisición, administración y disposición de bienes del Estado;

- Decreto Ley 2.565, que sustituye Decreto Ley 701, de 1974, que somete los terrenos forestales a las disposiciones que señala (normas sobre fomento forestal);

- Decreto Ley 3.274, que fija ley orgánica del Ministerio de Bienes Nacionales;

- Decreto Ley 3.557, que establece disposiciones sobre protección agrícola;

- Ley 18.248, que contiene el Código de Minería;

- Ley 18.362, que crea un sistema nacional de áreas silvestres protegidas del Es$\operatorname{tado}^{12}$.

Algunos IGT, principalmente del ámbito de la conservación natural y cultural (áreas silvestres protegidas y monumentos nacionales) revisten a su vez el carácter de IPT si se considera que pueden afectar a áreas importantes del territorio y fijan criterios de interés público más o menos permanentes para el uso del suelo en ellas.

Por último, en una visión más amplia de la gestión territorial cabe considerar las facultades de fiscalización que algunos cuerpos normativos establecen para los organismos principales o para organismos colaboradores de dicha gestión. Tal es el caso, por ejemplo, de la función de control de Carabineros de Chile conforme a la Ley de Caza, la Ley para la conservación de suelos, bosques y aguas, la Ley de Monumentos Nacionales o la Ley de Pesca y Acuicultura, entre otras.

De acuerdo a lo expuesto, se puede apreciar que la legislación chilena contempla diversos IPT e IGT, mayormente sectoriales, al igual que los organismos encargados de desarrollarlos y aplicarlos. Se puede decir que, en general, todos los ámbitos del quehacer humano están cubiertos en su 
ejercicio y fiscalización por la normativa orgánica, sectorial o propiamente territorial, aunque muchas veces se encuentran establecidas simplemente como facultades genéricas, más o menos imprecisas, de algún ministerio u organismo subordinado para regular y controlar ciertos usos del suelo, lo que lleva a que no haya límites claros entre las atribuciones de las distintas autoridades involucradas en la planificación, y sobre todo en la gestión. Esto ha llevado a plantear la necesidad de adaptar o transformar significativamente el mapa de las responsabilidades institucionales para dar cuenta de las transformaciones territoriales actuales, las que en el caso de los espacios urbanos por ejemplo, corresponden a verdaderas mutaciones territoriales (Arenas, 2007a). Las responsabilidades por niveles y por sectores se prestan actualmente a confusión por lo que entre las tareas pendientes se encuentra precisamente aquella de mejorar el mapa de las responsabilidades institucionales en estas materias (Arenas, 2007b).

En muchos casos la situación descrita permite que se diluyan las responsabilidades administrativas y políticas, dificultando tanto la búsqueda de coherencia entre usos del suelo contiguos como la compatibilidad en el caso de usos que entran en conflicto. El ordenamiento territorial debe contar con reglas claras para los agentes públicos o privados que se interesen en desarrollar determinadas actividades sobre el suelo. La claridad de reglas facilita la denominada accountability o control ciudadano sobre la gestión de las autoridades en estas materias y la gobernanza territorial, aspectos que pueden dar sostenibilidad a las unidades político-administrativas (Arenas et al., 2007).

Por último, es importante recalcar que las normas directas de ordenamiento territorial solo prevén IPT e IGT para áreas declaradas como urbanas, de modo que la mayor parte del territorio, excluido de dichas áreas, queda sin una regulación territorial directa y sujeta simplemente a lo que dispongan los diferentes organismos sectoriales en su planificación y gestión por cada rubro o actividad que administran.

\section{Consideraciones finales}

El análisis de la legislación chilena en las materias tratadas en este trabajo no es tan alentador como se desearía, dado que esta no presenta sistematización en materia de ordenamiento territorial, con la sola y reducida excepción del ordenamiento y la planificación urbana. Esta última tampoco se inserta dentro de un ordenamiento integral del territorio. En los diversos y numerosos textos legales y reglamentarios que se han considerado como normas relevantes en dicha materia, se encuentran establecidos múltiples organismos competentes y con funciones y atribuciones también diversas, para la regulación de los posibles usos del suelo. Además, no existen principios rectores en base a los cuales se puedan definir, en la práctica, los usos autorizados del suelo y los permisos que se deben dictar en consecuencia.

La planificación y gestión del territorio se encuentra atribuida en su mayor parte a los organismos sectoriales nacionales y regionales, que hacen las veces de planificadores y gestores de las actividades sectoriales. Sus funciones y atribuciones, al recaer sobre un mismo territorio, se traslapan necesariamente. En el caso de funciones y atribuciones establecidas en forma genérica, no existe una real coordinación de todo el aparato administrativo para delimitar exactamente los alcances de la regulación y control de uno u otro organismo competente.

Pese a la existencia de principios administrativos que establecen el deber de actuar eficientemente, hemos constatado pocos casos en que existe una adecuada coordinación entre las actividades sectoriales. Cuando esta coordinación existe, ella se relaciona más con la voluntad política que con la aplicación de los principios mencionados.

En la situación actual, la planificación del territorio en Chile no es integral sino compartimentada, de acuerdo con las disposiciones que dictan los organismos sectoriales, sin que estas sean necesariamente coordinadas. Los permisos ambientales se limitan por ahora a garantizar, de manera 
exhaustiva, que cada uno de los organismos sectoriales constate el cumplimiento de sus requisitos propios, no asegurando así el uso adecuado del suelo en todas sus partes, sino que por segmentos estancos y por actividades también separadas. Tanto la planificación territorial como la ambiental debieran tener un carácter transversal que actualmente no tienen, lo que genera problemas de coordinación y de coherencia entre ambas.

El borde costero tal como está concebido en la legislación chilena, tiene una extensión muy reducida sujeta a regulación específica, lo que no permite abarcar de una manera adecuada la planificación de lo que se debería considerar una zona costera. Para su adecuada delimitación deberían incorporarse criterios ambientales y funcionales y no solo administrativos, que permitan determinar para cado tramo del litoral, la extensión más adecuada para un manejo más satisfactorio. Esto no pretende afectar ni desestabilizar la propiedad privada ni la pública, o el ejercicio de las facultades que ellas brindan, sino asegurarlas en forma sustentable y permanente en el tiempo. Para ello es consustancial el conocimiento científico y técnico detallado de toda esa zona de interacción.

La institucionalidad para el uso del borde costero no obedece actualmente a una política que permita su regulación permanente e integral. Por ahora parece obedecer más a la finalidad, no despreciable pero restringida, de realizar una gestión eficiente y sustentable de un ámbito territorialmente reducido, conforme a criterios recomendados pero no obligatorios para los agentes involucrados. Este enfoque restringido de planificación costera se adapta a la regulación sectorial del uso de recursos del litoral, pero no es suficiente a la escala necesaria para el ordenamiento territorial de la zona costera.

Las actuales condiciones institucionales para el ordenamiento territorial de la zona costera en Chile se podrían mejorar con la adopción de algunos principios de política, tales como los propuestos en Arenas $(2007 \mathrm{~b})$ : solidaridad territorial, subsidiaridad, complementariedad y prevención. Sin embargo, más allá de la coherencia que se pueda conseguir usando los principios de política señalados y los instrumentos disponibles en materia de planificación y gestión territorial, parece necesario un ajuste respecto de la "localización" administrativa de alguno de los instrumentos disponibles y del "mapa" de las responsabilidades institucionales.

Finalmente, la identificación de los problemas institucionales y jurídicos que hoy presenta el ordenamiento territorial del espacio costero chileno, hace imprescindible un esfuerzo mancomunado de los actores involucrados, para mejorar la situación descrita. Parea estos efectos, puede ser altamente provechoso considerar experiencias internacionales exitosas de implementación de normativas de ordenamiento territorial.

* Este artículo es parte de los resultados del Proyecto FONDECYT No 1060745 "Evaluación de la fragilidad ambiental con fines de ordenamiento y planificación territorial en la zona costera de la Región del Maule".

\section{Referencias bibliográficas}

ANDRADE, B. Los espacios litorales: definiciones, actores, desafíos, perspectivas. En: ARENAS, F. y CÁCERES, G. (Eds). Ordenamiento del territorio en Chile. Desafíos y urgencias para el tercer milenio. Santiago de Chile: Ediciones Universidad Católica de Chile, 2001, p. 21-30.

ANDRADE, B.; ARENAS, F. y QUENSE, J. La costa oriental de la Isla Grande de Chiloé: un caso de análisis para el ordenamiento territorial. Revista Geográfica de Valparaíso, 2000, $\mathrm{N}^{\circ} 31$, p. 45-54.

ANDRADE, B. y CASTRO, C. La zona costera: evolución geomorfológica natural e interferencia antrópica. En: XII Jornadas Nacionales de Cultura, Chile y el Mar, Comisión 3 (Santiago, 4 al 6 de noviembre, 1987). Santiago de Chile: Pontificia Universidad Católica de Chile, Consejo de Rectores de las Universidades Chilenas, 1987.

ARENAS, F. Reconfiguración espacial y adaptación institucional: un ajuste pendiente en el caso de los espacios metropolitanos chilenos. En: DE MATTOS, C. e HIDALGO, R. (Eds.). Santiago de Chile. Movilidad espa- 
cial y reconfiguración metropolitana. Santiago de Chile: Instituto de Estudios Urbanos, Pontificia Universidad Católica de Chile, Colección EURE-LIBROS - Instituto de Geografía, Pontificia Universidad Católica de Chile, Serie GEOlibros Nº, 2007a, p. 177-188.

ARENAS, F. Sueños para el 2050. Revista Universitaria Pontificia Universidad Católica de Chile, Dossier Descentralización, 2007b, $N^{\circ} 96$, p. 52-58.

ARENAS, F.; HIDALGO, R.; ORELLANA, A. y ALIAGA, G. Propuesta de nuevos criterios pare redefinir unidades político administrativas regionales en Chile. En: PUCSUBDERE-SEGPRES-MIDEPLAN. Camino al Bicentenario, propuesta para Chile. Concurso Políticas Públicas 2007. Santiago de Chile: Pontificia Universidad Católica de Chile, Dirección de Asuntos Públicos - Ministerio del Interior, Subsecretaría de Desarrollo Regional (SUBDERE) - Ministerio Secretaría General de la Presidencia (SEGPRES) - Ministerio de Planificación (MIDEPLAN), 2007, Capítulo 11, p. 349-374.

BARRAGÁN, J. M.; CASTRO, C. y ALVARADO, C. La zona costera chilena: caracterización geográfica y estado de la gestión. Revista Geográfica de Valparaíso, 2004, $\mathrm{N}^{\circ} 35$, p. 17-35.

BARRAGÁN, J. M.; CASTRO, C. y ALVARADO, C. Towards Integrated Coastal Zone Management in Chile. Coastal Management, 2005, No33, p. 1-24.

BARRAGÁN, J. M.; CHICA, A. y PÉREZ, M. L. Propuesta de estrategia andaluza de gestión integrada de zonas costeras. España: Junta de Andalucía, Consejería del Medio Ambiente, 2008.

BECET, J. M. L'aménagement du littoral. París: P.U.F. Col. Que sais-je?, 1987.

CASTRO, C. y MORALES, E. La zona costera. Medio natural y ordenación integrada. Santiago de Chile: Instituto de Geografía, Pontificia Universidad Católica de Chile, Serie GEOlibros N 5, 2006.

COMISIÓN MUNDIAL DEL MEDIO AMBIENTE Y DEL DESARROLLO (CMMAD). Nuestro futuro común. Madrid: Alianza, 1987.

EVERT, K.J. (Ed.). Diccionario - paisaje y urbanismo: léxico multilingüe de planificación, diseño, y protección del medio ambiente. Berlín: Springer, 2001.

GUIJÓN, R. Diagnóstico y aplicabilidad de las normas jurídicas de ordenamiento territorial en la zona costera de la Región del Maule. Seminario de grado (Licenciatura en Geografía). Santiago de Chile: Pontificia Universidad Católica de Chile, Instituto de Geografía, 2007.

MINISTERIO DE BIENES NACIONALES DE CHILE. Las playas para todos los chilenos. Manual para la fijación de los accesos. Santiago de Chile: Ministerio de Bienes Nacionales de Chile, 1997.

PUJADAS, R. y FONT, J. Ordenación y planificación territorial. Madrid: Síntesis, 1998. 
Anexo $\mathrm{N}^{\circ} 1$

LISTADO DE NORMAS DE ORDENAMIENTO TERRITORIAL ANALIZADAS, ORDENADAS POR MATERIA

\begin{tabular}{|c|c|c|}
\hline Materia & $\begin{array}{l}\text { Norma general de } \\
\text { ordenamiento territorial }\end{array}$ & Organismos regulados \\
\hline Acuicultura & $\begin{array}{l}\text { DS 290, 1993, Economía, } \\
\text { Reglamento de Concesiones y } \\
\text { Autorizaciones de Acuicultura }\end{array}$ & $\begin{array}{l}\text { 1. DIRECTEMAR } \\
\text { 2. SERNAPESCA } \\
\text { 3. DGA } \\
\text { 4. Subsecretaría de Pesca } \\
\text { 5. Ministerio de Defensa Nacional }\end{array}$ \\
\hline Acuicultura & $\begin{array}{l}\text { DS 320, 2001, Economía, } \\
\text { Reglamento Ambiental para la } \\
\text { Acuicultura }\end{array}$ & $\begin{array}{l}\text { 1. Subsecretaría de Pesca } \\
\text { 2. SERNAPESCA } \\
\text { 3. DIRECTEMAR o Autoridad } \\
\text { Marítima }\end{array}$ \\
\hline Acuicultura & $\begin{array}{l}\text { DS 314, 2004, Economía, } \\
\text { Reglamento de Actividades de } \\
\text { Acuicultura en Áreas de Manejo y } \\
\text { Explotación de Recursos Bentónicos }\end{array}$ & $\begin{array}{l}\text { 1. SERNAPESCA } \\
\text { 2. Subsecretaría de Pesca } \\
\text { 3. Ministerio de Defensa Nacional } \\
\text { 4. DIRECTEMAR }\end{array}$ \\
\hline Aeródromos & $\begin{array}{l}\text { DS 173, 2004, Defensa, } \\
\text { Reglamento de Aeródromos }\end{array}$ & $\begin{array}{l}\text { 1. Dirección General de Aeronáutica } \\
\text { Civil }\end{array}$ \\
\hline $\begin{array}{l}\text { Aeródromos y } \\
\text { aeropuertos }\end{array}$ & Ley 18.916, Código Aeronáutico & $\begin{array}{l}\text { 1. Dirección General de Aeronáutica } \\
\text { Civil } \\
\text { 2. Ministerio de Defensa Nacional } \\
\text { 3. Ministerio de Vivienda y } \\
\text { Urbanismo } \\
\text { 4. Junta de Aeronáutica Civil } \\
\text { 5. Juzgados de aviación }\end{array}$ \\
\hline Aguas & $\begin{array}{l}\text { DFL 1.122, 1981, Justicia, Código } \\
\text { de Aguas }\end{array}$ & $\begin{array}{l}\text { 1. DGA } \\
\text { 2. Ministerio de Obras Públicas } \\
\text { 3. COREMA o CONAMA }\end{array}$ \\
\hline Aguas Iluvias & $\begin{array}{l}\text { Ley } 19.525 \text {, regula sistemas de } \\
\text { evacuación y drenaje de aguas } \\
\text { Iluvias }\end{array}$ & $\begin{array}{l}\text { 1. Ministerio de Obras Públicas } \\
\text { 2. Ministerio de Vivienda y } \\
\text { Urbanismo }\end{array}$ \\
\hline Aguas minerales & $\begin{array}{l}\text { DS 106, 1997, Salud, Reglamento } \\
\text { de Aguas Minerales }\end{array}$ & $\begin{array}{l}\text { 1. Ministerio de Salud } \\
\text { 2. SEREMI de Salud o Ministerio de } \\
\text { Salud (en cuanto sucesores del } \\
\text { Servicio Nacional de Salud) } \\
\text { 3. DGA }\end{array}$ \\
\hline Bienes del Estado & $\begin{array}{l}\text { DL } 1.939 \text {, normas sobre } \\
\text { adquisición, administración y } \\
\text { disposición de bienes del Estado }\end{array}$ & $\begin{array}{l}\text { 1. Ministerio de Bienes Nacionales } \\
\text { 2. Intendente Regional } \\
\text { 3. Ministerio de Agricultura }\end{array}$ \\
\hline $\begin{array}{l}\text { Bienes nacionales de } \\
\text { uso público }\end{array}$ & $\begin{array}{l}\text { DS } 609,1978, \text { Tierras y } \\
\text { Colonización, fija normas para } \\
\text { establecer los deslindes de los } \\
\text { bienes nacionales de uso público } \\
\text { que constituyen los cauces de los } \\
\text { ríos, lagos y esteros }\end{array}$ & $\begin{array}{l}\text { 1. Ministerio de Bienes Nacionales } \\
\text { 2. Ministerio de Obras Públicas }\end{array}$ \\
\hline Borde costero & $\begin{array}{l}\text { DS 475, 1994, Defensa, establece } \\
\text { Política Nacional de Uso del Borde } \\
\text { Costero del Litoral de la República y } \\
\text { crea comisión nacional que indica }\end{array}$ & 1. CNUBC \\
\hline
\end{tabular}




\begin{tabular}{|c|c|c|}
\hline Materia & $\begin{array}{l}\text { Norma general de } \\
\text { ordenamiento territorial }\end{array}$ & Organismos regulados \\
\hline Borde costero & $\begin{array}{l}\text { Orden ministerial 1, 1997, Defensa, } \\
\text { dicta instrucciones sobre } \\
\text { otorgamiento de concesiones } \\
\text { marítimas que indica }\end{array}$ & $\begin{array}{l}\text { 1. Subsecretaría de Marina } \\
\text { 2. DIRECTEMAR (autoridad } \\
\text { marítima)3. SERNATUR }\end{array}$ \\
\hline Borde costero & $\begin{array}{l}\text { Orden ministerial 2, 1998, Defensa, } \\
\text { instruye sobre prohibición de } \\
\text { ingreso y tránsito de vehículos en } \\
\text { toda la costa del litoral de la } \\
\text { República, sus playas, terrenos de } \\
\text { playa, en ríos y lagos y demás } \\
\text { bienes nacionales de competencia } \\
\text { de este ministerio }\end{array}$ & $\begin{array}{l}\text { 1. DIRECTEMAR } \\
\text { 2. Subsecretaría de Marina } \\
\text { 3. Armada }\end{array}$ \\
\hline Borde costero & $\begin{array}{l}\text { Oficio gab. Pres. 001, 2005, } \\
\text { CNUBC, reglamento interno de } \\
\text { funcionamiento de la Comisión } \\
\text { Regional de Uso del Borde Costero } \\
\text { de la República }\end{array}$ & $\begin{array}{l}\text { 1. CRUBC } \\
\text { 2. Oficinas Técnicas Regionales, en } \\
\text { particular } \\
\text { 3. Gobiernos Regionales } \\
\text { 4. CNUBC5. Ministerio de Defensa } \\
\text { Nacional }\end{array}$ \\
\hline Borde costero & $\begin{array}{l}\text { Ley } 20.062 \text {, regulariza situación de } \\
\text { ocupaciones irregulares en borde } \\
\text { costero de sectores que indica, e } \\
\text { introduce modificaciones al DL } \\
1.939 \text {, de } 1977\end{array}$ & $\begin{array}{l}\text { 1. Ministerio de Bienes Nacionales } \\
\text { 2. Armada }\end{array}$ \\
\hline Bosques & $\begin{array}{l}\text { DS 4.363, 1931, Tierras y } \\
\text { Colonización, aprueba texto } \\
\text { definitivo de la Ley de Bosques }\end{array}$ & $\begin{array}{l}\text { 1. CONAF } \\
\text { 2. Ministerio de Bienes Nacionales } \\
\text { 3. Ministerio de Agricultura } \\
\text { 4. Municipalidad } \\
\text { 5. SAG } \\
\text { 6. Gobernación Provincial } \\
\text { 7. Carabineros }\end{array}$ \\
\hline Bosques & $\begin{array}{l}\text { DS } 2.374,1937, \text { Tierras y } \\
\text { Colonización, reglamentación de } \\
\text { explotación de bosques en hoyas } \\
\text { hidrográficas declaradas forestales }\end{array}$ & 1. SAG \\
\hline Bosques & $\begin{array}{l}\text { DS } 2.467,1937, \text { Ministerio de } \\
\text { Tierras y Colonización, normas } \\
\text { sobre terrenos que no pueden ser } \\
\text { declarados forestales }\end{array}$ & 一- \\
\hline Bosques & $\begin{array}{l}\text { DS 5, 1972, Agricultura, aprueba } \\
\text { reglamento para la explotación de } \\
\text { pino insigne en la Provincia de } \\
\text { Maule }\end{array}$ & 1. CONAF \\
\hline Bosques, roce a fuego & $\begin{array}{l}\text { DS } 276,1980, \text { Agricultura, } \\
\text { reglamenta requisitos y la época } \\
\text { para el roce a fuego }\end{array}$ & $\begin{array}{l}\text { 1. CONAF } \\
\text { 2. Carabineros } \\
\text { 3. SAG }\end{array}$ \\
\hline Buceo & $\begin{array}{l}\text { DS 752, 1982, Defensa, reglamento } \\
\text { de buceo para buzos profesionales }\end{array}$ & $\begin{array}{l}\text { 1. DIRECTEMAR } \\
\text { 2. Armada }\end{array}$ \\
\hline
\end{tabular}




\begin{tabular}{|c|c|c|}
\hline Materia & $\begin{array}{l}\text { Norma general de } \\
\text { ordenamiento territorial }\end{array}$ & Organismos regulados \\
\hline Catástrofes & $\begin{array}{l}\text { Ley } 16.282 \text {, fija disposiciones para } \\
\text { casos de sismos o catástrofes, } \\
\text { establece normas para la } \\
\text { reconstrucción de la zona afectada } \\
\text { por el sismo de } 28 \text { de marzo de } \\
1965 \text { y modifica la Ley } N^{0} 16.250\end{array}$ & $\begin{array}{l}\text { 1. Ministerio del Interior } \\
\text { 2. Municipalidades } \\
\text { 3. Ministerio de Defensa Nacional } \\
\text { 4. Comités Comunales de Emergencia } \\
\text { 5. Ministerio de Vivienda y } \\
\text { Urbanismo } \\
\text { 6. Dirección General de Aguas } \\
\text { 7. Empresas autónomas del Estado }\end{array}$ \\
\hline Catástrofes & $\begin{array}{l}\text { Ley } 18.415, \text { ley orgánica } \\
\text { constitucional de los estados de } \\
\text { excepción }\end{array}$ & $\begin{array}{l}\text { 1. Presidente de la República } \\
\text { 2. Ministerio del Interior } \\
\text { 3. Ministerio de Defensa Nacional } \\
\text { 4. Comandantes en Jefe o jefes de la } \\
\text { Defensa Nacional, delegados } \\
\text { 5. Gobernador respectivo } \\
\text { 6. Juez de letras en lo civil } \\
\text { competente }\end{array}$ \\
\hline Catástrofes & $\begin{array}{l}\text { Ley } 19.061 \text {, establece normas sobre } \\
\text { fomento a obras de riego en zonas } \\
\text { afectadas por sismos o catástrofes }\end{array}$ & 1. Comisión Nacional de Riego \\
\hline Catástrofes & $\begin{array}{l}\text { DS 156, 2002, Interior, aprueba } \\
\text { Plan Nacional de Protección Civil; y } \\
\text { deroga Decreto Supremo de Interior } \\
\text { No }^{\circ} 155 \text {, de 1977, que aprobó el } \\
\text { Plan Nacional de Emergencia }\end{array}$ & $\begin{array}{l}\text { 1. ONEMI } \\
\text { 2. Ministerio del Interior } \\
\text { 3. Comités de Protección Civil }\end{array}$ \\
\hline Caza & $\begin{array}{l}\text { Ley } 19.473 \text {, sustituye texto de la Ley } \\
4.601 \text {, sobre caza, y artículo } 609 \\
\text { del Código Civil }\end{array}$ & $\begin{array}{l}\text { 1. Ministerio de Agricultura } \\
\text { 2. SAG } \\
\text { 3. Subsecretaría de Pesca } \\
\text { 4. Ministerio de Economía } \\
\text { 5. Carabineros de Chile } \\
\text { 6. Autoridad Marítima } \\
\text { 7. SERNAPESCA } \\
\text { 8. Entidad que el Estado designe } \\
\text { como administradora del SNASPE } \\
\text { (CONAF) }\end{array}$ \\
\hline Caza & $\begin{array}{l}\text { DS 5, 1998, Agricultura, } \\
\text { Reglamento de la Ley de Caza }\end{array}$ & $\begin{array}{l}\text { 1. Ministerio de Agricultura } \\
\text { 2. SAG } \\
\text { 3. Carabineros de Chile } \\
\text { 4. Autoridad Marítima } \\
\text { 5. SERNAPESCA } \\
\text { 6. Entidad que el Estado designe } \\
\text { como administradora del SNASPE } \\
\text { (CONAF) }\end{array}$ \\
\hline $\begin{array}{l}\text { Comunidades } \\
\text { agrícolas }\end{array}$ & $\begin{array}{l}\text { DFL 5, 1967, Agricultura, modifica, } \\
\text { complementa y fija texto refundido } \\
\text { del D.F.L. R.R.A n } \text { n }^{\circ} 19, \\
\text { comunidades agrícolas }\end{array}$ & $\begin{array}{l}\text { 1. Ministerio de Bienes Nacionales } \\
\text { 2. Juez de letras en lo civil } \\
\text { 3. SAG }\end{array}$ \\
\hline $\begin{array}{l}\text { Concesiones } \\
\text { marítimas }\end{array}$ & $\begin{array}{l}\text { DFL 340, 1969, Hacienda, Ley de } \\
\text { Concesiones Marítimas }\end{array}$ & $\begin{array}{l}\text { 1. Subsecretaría de Marina } \\
\text { 2. DIRECTEMAR }\end{array}$ \\
\hline $\begin{array}{l}\text { Concesiones } \\
\text { marítimas }\end{array}$ & $\begin{array}{l}\text { DS 2, 2005, Defensa, nuevo } \\
\text { Reglamento de Concesiones } \\
\text { Marítimas }\end{array}$ & $\begin{array}{l}\text { 1. Subsecretaría de Marina } \\
\text { 2. DIRECTEMAR }\end{array}$ \\
\hline
\end{tabular}




\begin{tabular}{|c|c|c|}
\hline Materia & $\begin{array}{l}\text { Norma general de } \\
\text { ordenamiento territorial }\end{array}$ & Organismos regulados \\
\hline $\begin{array}{l}\text { Conservación de } \\
\text { suelos, bosques, aguas }\end{array}$ & $\begin{array}{l}\text { Ley } 18.378 \text {, deroga Ley } 15.020 \text { y } \\
\text { DFL RRA 26, } 1963 \text {, y establece } \\
\text { sanciones que señala }\end{array}$ & $\begin{array}{l}\text { 1. Ministerio de Agricultura } \\
\text { 2. SERNATUR } \\
\text { 3. CONAF } \\
\text { 4. Carabineros }\end{array}$ \\
\hline $\begin{array}{l}\text { Contaminación } \\
\text { acuática }\end{array}$ & $\begin{array}{l}\text { DS 1, 1992, Defensa, Reglamento } \\
\text { para el Control de la Contaminación } \\
\text { Acuática }\end{array}$ & $\begin{array}{l}\text { 1. DIRECTEMAR o Autoridad } \\
\text { Marítima }\end{array}$ \\
\hline Deportes náuticos & $\begin{array}{l}\text { DS 87, 1997, Defensa, Reglamento } \\
\text { General de Deportes Náuticos }\end{array}$ & 1. DIRECTEMAR \\
\hline Desarrollo indígena & $\begin{array}{l}\text { Ley } 19.253 \text {, establece normas sobre } \\
\text { protección, fomento y desarrollo de } \\
\text { los indígenas, y crea la Corporación } \\
\text { Nacional de Desarrollo Indígena }\end{array}$ & $\begin{array}{l}\text { 1. CONADI } \\
\text { 2. Conservadores de Bienes Raíces } \\
\text { 3. Jueces de letras en lo civil } \\
\text { 4. SEREMI de Vivienda y Urbanismo } \\
\text { 5. MIDEPLAN } \\
\text { 6. Gobiernos Regionales } \\
\text { 7. Municipalidades }\end{array}$ \\
\hline $\begin{array}{l}\text { Dirección General de } \\
\text { Territorio Marítimo y } \\
\text { de Marina Mercante }\end{array}$ & $\begin{array}{l}\text { DFL 292, 1953, Hacienda, ley } \\
\text { orgánica de la Dirección de } \\
\text { Territorio Marítimo y Marina } \\
\text { Mercante }\end{array}$ & $\begin{array}{l}\text { 1. DIRECTEMAR o Autoridad } \\
\text { Marítima } \\
\text { 2. Ministerio de Defensa Nacional } \\
\text { 3. Carabineros } \\
\text { 4. Servicio Nacional de Aduanas } \\
\text { 5. Policía de Investigaciones }\end{array}$ \\
\hline $\begin{array}{l}\text { División de predios } \\
\text { rústicos }\end{array}$ & $\begin{array}{l}\text { DL 3.516, establece normas sobre } \\
\text { división de predios rústicos }\end{array}$ & $\begin{array}{l}\text { 1. SEREMI de Vivienda y Urbanismo } \\
\text { 2. SAG } \\
\text { 3. Municipalidades }\end{array}$ \\
\hline Fomento forestal & $\begin{array}{l}\text { DL 2.565, sustituye Decreto Ley } \\
701 \text {, de } 1974 \text {, que somete los } \\
\text { terrenos forestales a las } \\
\text { disposiciones que señala }\end{array}$ & 1. CONAF \\
\hline Fomento forestal & $\begin{array}{l}\text { DS 259, 1980, Agricultura, } \\
\text { reglamento del Decreto Ley 701, de } \\
\text { 1974, sobre fomento forestal }\end{array}$ & 1. CONAF \\
\hline Fomento forestal & $\begin{array}{l}\text { DS 193, 1998, Agricultura, } \\
\text { reglamento general del DL 701, de } \\
\text { 1974, sobre fomento forestal }\end{array}$ & $\begin{array}{l}\text { 1. CONAF } \\
\text { 2. Carabineros }\end{array}$ \\
\hline $\begin{array}{l}\text { Gobierno y } \\
\text { administración } \\
\text { regional }\end{array}$ & $\begin{array}{l}\text { DFL } 1,2005 \text {, Interior, fija texto de la } \\
\text { Ley } 19.175 \text {, OC de Gobierno y } \\
\text { Administración Regional }\end{array}$ & $\begin{array}{l}\text { 1. Intendente regional } \\
\text { 2. Gobernador provincial } \\
\text { 3. Gobierno regional } \\
\text { 4. Ministerio de Planificación } \\
\text { 5. Órganos y servicios de la } \\
\text { Administración Pública nacional, } \\
\text { empresas en que tenga intervención } \\
\text { el Fisco por aportes de capital y los } \\
\text { servicios públicos } \\
\text { 6. Municipalidades } \\
\text { 7. SEREMI de Vivienda y Urbanismo } \\
\text { 8. Consejo regional, como órgano del } \\
\text { gobierno regional } \\
\text { 9. Consejo Económico y Social } \\
\text { Provincial }\end{array}$ \\
\hline
\end{tabular}




\begin{tabular}{|c|c|c|}
\hline Materia & $\begin{array}{l}\text { Norma general de } \\
\text { ordenamiento territorial }\end{array}$ & Organismos regulados \\
\hline & & $\begin{array}{l}\text { 10. Secretarías Regionales } \\
\text { Ministeriales } \\
\text { 11. Ministerios, servicios públicos, } \\
\text { gobiernos regionales y } \\
\text { municipalidades, en general } \\
\text { 12. Consejo coordinador regional de } \\
\text { acción municipal, en regiones que } \\
\text { tengan áreas metropolitanas }\end{array}$ \\
\hline Lagos navegables & $\begin{array}{l}\text { DS } 11,1998 \text {, Defensa, fija nómina } \\
\text { oficial de lagos navegables por } \\
\text { buques de más de } 100 \text { toneladas }\end{array}$ & 1. DIRECTEMAR \\
\hline Medio ambiente & $\begin{array}{l}\text { Ley } 19.300 \text {, sobre Bases Generales } \\
\text { del Medio Ambiente }\end{array}$ & $\begin{array}{l}\text { 1. CONAMA } \\
\text { 2. COREMA } \\
\text { 3. Organismos con competencia } \\
\text { ambiental } \\
\text { 4. MIDEPLAN } \\
\text { 5. Gobernadores provinciales } \\
\text { 6. Municipalidades } \\
\text { 7. Organizaciones ciudadanas y } \\
\text { personas naturales } \\
\text { 8. Ministerio Secretaría General de la } \\
\text { Presidencia } \\
\text { 9. Ministerio de Salud }\end{array}$ \\
\hline $\begin{array}{l}\text { Medio ambiente, } \\
\text { emisiones }\end{array}$ & $\begin{array}{l}\text { DS } 185,1991 \text {, Secretaría General de } \\
\text { la Presidencia, reglamenta } \\
\text { funcionamiento de establecimientos } \\
\text { emisores de anhídrido sulfuroso, } \\
\text { material particulado y arsénico en } \\
\text { todo el territorio de la República }\end{array}$ & $\begin{array}{l}\text { 1. Comisión Interministerial de } \\
\text { Calidad del Aire } \\
\text { 2. Ministerio de Salud } \\
\text { 3. Ministerio de Agricultura } \\
\text { 4. Servicios sectoriales de salud o } \\
\text { agricultura } \\
\text { 5. Intendente regional } \\
\text { 6. COREMA }\end{array}$ \\
\hline $\begin{array}{l}\text { Medio ambiente, } \\
\text { normas de calidad y } \\
\text { de emisión }\end{array}$ & $\begin{array}{l}\text { DS 93, 1995, Secretaría General de } \\
\text { la Presidencia, reglamento para la } \\
\text { dictación de normas de calidad } \\
\text { ambiental y de emisión }\end{array}$ & $\begin{array}{l}\text { 1. Ministerio Secretaría General de la } \\
\text { Presidencia } \\
\text { 2. CONAMA } \\
\text { 3. COREMA } \\
\text { 4. Personas naturales o jurídicas en } \\
\text { general }\end{array}$ \\
\hline $\begin{array}{l}\text { Medio ambiente, } \\
\text { planes de prevención } \\
\text { y contaminación }\end{array}$ & $\begin{array}{l}\text { DS 94, 1995, Secretaría General de } \\
\text { la Presidencia, reglamento que fija } \\
\text { el procedimiento y etapas para } \\
\text { establecer planes de prevención y } \\
\text { descontaminación }\end{array}$ & $\begin{array}{l}\text { 1. CONAMA } \\
\text { 2. Personas naturales o jurídicas en } \\
\text { general } \\
\text { 3. COREMA } \\
\text { 4. Ministerio Secretaría General de la } \\
\text { Presidencia }\end{array}$ \\
\hline Medio ambiente, SEIA & $\begin{array}{l}\text { DS 95, 2001, Secretaría General de } \\
\text { la Presidencia, modifica Reglamento } \\
\text { del Sistema de Evaluación de } \\
\text { Impacto Ambiental }\end{array}$ & $\begin{array}{l}\text { 1. CONAMA } \\
\text { 2. COREMA } \\
\text { 3. Órganos de la administración del } \\
\text { Estado con competencia ambiental } \\
\text { 4. Organizaciones ciudadanas con } \\
\text { personalidad jurídica y personas } \\
\text { naturales directamente afectadas por } \\
\text { un proyecto }\end{array}$ \\
\hline
\end{tabular}




\begin{tabular}{|c|c|c|}
\hline Materia & $\begin{array}{l}\text { Norma general de } \\
\text { ordenamiento territorial }\end{array}$ & Organismos regulados \\
\hline Minería & Ley 18.248, Código de Minería & $\begin{array}{l}\text { 1. Juez de letras en lo civil respectivo } \\
\text { 2. Gobernador respectivo } \\
\text { 3. SEREMI de Vivienda y Urbanismo } \\
\text { 4. Intendente respectivo } \\
\text { 5. Dirección de Fronteras y Límites } \\
\text { 6. Ministerio de Defensa Nacional } \\
\text { 7. Presidente de la República, } \\
\text { posiblemente a través del Ministerio } \\
\text { de Educación } \\
\text { 8. Ministerio de Minería } \\
\text { 9. Comisión Nacional de Energía } \\
\text { Nuclear } \\
\text { 10. Municipalidad respectiva (alcalde) } \\
\text { 11. SERNAGEOMIN } \\
\text { 12. Conservador de Minas }\end{array}$ \\
\hline $\begin{array}{l}\text { Ministerio de } \\
\text { Agricultura }\end{array}$ & $\begin{array}{l}\text { DFL 294, 1960, Hacienda, establece } \\
\text { funciones y estructura Ministerio de } \\
\text { Agricultura }\end{array}$ & 1. Ministerio de Agricultura \\
\hline $\begin{array}{l}\text { Ministerio de Bienes } \\
\text { Nacionales }\end{array}$ & $\begin{array}{l}\text { DL } 3.274 \text {, fija ley orgánica del } \\
\text { Ministerio de Bienes Nacionales }\end{array}$ & 1. Ministerio de Bienes Nacionales \\
\hline Ministerio de Defensa & $\begin{array}{l}\text { DS } 244,1976 \text {, Defensa, reglamento } \\
\text { orgánico del Ministerio de Defensa } \\
\text { Nacional }\end{array}$ & $\begin{array}{l}\text { 1. Ministerio de Defensa Nacional } \\
\text { 2. Subsecretarías, en particular }\end{array}$ \\
\hline $\begin{array}{l}\text { Ministerio de } \\
\text { Economía }\end{array}$ & $\begin{array}{l}\text { DFL } 88,1953, \text { Hacienda, adopta las } \\
\text { medidas que indica en relación con el } \\
\text { Ministerio de Economía y Comercio y } \\
\text { sus atribuciones y actividades }\end{array}$ & $\begin{array}{l}\text { 1. Ministerio de Economía } \\
\text { 2. Ministerio de Agricultura }\end{array}$ \\
\hline $\begin{array}{l}\text { Ministerio de la } \\
\text { Vivienda y Urbanismo }\end{array}$ & $\begin{array}{l}\text { Ley } 16.391 \text {, crea el Ministerio de } \\
\text { Vivienda y Urbanismo }\end{array}$ & $\begin{array}{l}\text { 1. Ministerio de Vivienda y } \\
\text { Urbanismo } \\
\text { 2. Municipalidades }\end{array}$ \\
\hline $\begin{array}{l}\text { Ministerio de la } \\
\text { Vivienda y Urbanismo }\end{array}$ & $\begin{array}{l}\text { DL } 1.305 \text {, reestructura y regionaliza } \\
\text { el Ministerio de Vivienda y } \\
\text { Urbanismo }\end{array}$ & $\begin{array}{l}\text { 1. Ministerio de Vivienda y } \\
\text { Urbanismo (importancia especial de } \\
\text { DDU y SEREMIs) }\end{array}$ \\
\hline Ministerio de Minería & $\begin{array}{l}\text { DFL 302, 1960, Hacienda, aprueba } \\
\text { disposiciones orgánicas y } \\
\text { reglamentarias del Ministerio de } \\
\text { Minería }\end{array}$ & 1. Ministerio de Minería \\
\hline $\begin{array}{l}\text { Ministerio de Obras } \\
\text { Públicas, caminos }\end{array}$ & $\begin{array}{l}\text { DFL 850, 1997, Obras Públicas, fija } \\
\text { el texto refundido, coordinado y } \\
\text { sistematizado de la Ley No } 15.840 \text {, } \\
\text { de } 1964 \text { (orgánica del MOP), y del } \\
\text { D.F.L. (MOP) N N } 206 \text {, de } 1960 \\
\text { (sobre construcción y conservación } \\
\text { de caminos) }\end{array}$ & $\begin{array}{l}\text { 1. Ministerio de Obras Públicas } \\
\text { 2. Municipalidades } \\
\text { 3. Intendentes y gobernadores } \\
\text { 4. Ministerio de Vivienda y } \\
\text { Urbanismo }\end{array}$ \\
\hline $\begin{array}{l}\text { Ministerio de } \\
\text { Planificación }\end{array}$ & $\begin{array}{l}\text { Ley } 18.989 \text {, crea el Ministerio de } \\
\text { Planificación y Cooperación }\end{array}$ & $\begin{array}{l}\text { 1. MIDEPLAN } \\
\text { 2. SEREMI de Planificación } \\
\text { 3. FOSIS } \\
\text { 4. AGCI } \\
\text { 5. Ministerio de Relaciones Exteriores } \\
\text { 6. Ministerio de Hacienda }\end{array}$ \\
\hline
\end{tabular}




\begin{tabular}{|c|c|c|}
\hline Materia & $\begin{array}{c}\text { Norma general de } \\
\text { ordenamiento territorial }\end{array}$ & Organismos regulados \\
\hline Ministerios & $\begin{array}{l}\text { DFL } 7.912,1927 \text {, Interior, decreto } \\
\text { que organiza las secretarías de } \\
\text { Estado }\end{array}$ & $\begin{array}{l}\text { 1. Ministerio del Interior } \\
\text { 2. Ministerio de Defensa Nacional } \\
\text { 3. Ministerio de Obras Públicas } \\
\text { 4. Ministerio de Salud Pública }\end{array}$ \\
\hline $\begin{array}{l}\text { Monumentos } \\
\text { nacionales }\end{array}$ & $\begin{array}{l}\text { Ley } 17.288 \text {, sobre Monumentos } \\
\text { Nacionales }\end{array}$ & $\begin{array}{l}\text { 1. Consejo de Monumentos } \\
\text { Nacionales } \\
\text { 2. Autoridades civiles, militares y } \\
\text { Carabineros } \\
\text { 3. Municipalidades } \\
\text { 4. Intendencias y Gobernaciones }\end{array}$ \\
\hline $\begin{array}{l}\text { Monumentos } \\
\text { nacionales }\end{array}$ & $\begin{array}{l}\text { DS exento 311, 1999, Educación, } \\
\text { declara monumento histórico } \\
\text { subacuático que indica, cuya } \\
\text { antigüedad sea mayor de } 50 \text { años }\end{array}$ & ————— \\
\hline Municipalidades & $\begin{array}{l}\text { DFL } 1,2006 \text {, Interior, fija texto de la } \\
\text { Ley } 18.695 \text {, OC de Municipalidades }\end{array}$ & $\begin{array}{l}\text { 1. Municipalidad } \\
\text { 2. Intendente regional } \\
\text { 3. Secretaría Comunal de } \\
\text { Planificación } \\
\text { 4. Unidad de obras municipales } \\
\text { 5. Alcalde } \\
\text { 6. Concejo } \\
\text { 7. Consejo económico y social comunal }\end{array}$ \\
\hline Navegación & $\begin{array}{l}\text { DL } 2.222 \text {, sustituye Ley de } \\
\text { Navegación }\end{array}$ & 1. DIRECTEMAR \\
\hline ONEMI, catástrofes & $\begin{array}{l}\text { DL 369, crea la Oficina Nacional de } \\
\text { Emergencia, dependiente del } \\
\text { Ministerio del Interior }\end{array}$ & $\begin{array}{l}\text { 1. ONEMI } \\
\text { 2. Ministerio del Interior }\end{array}$ \\
\hline ONEMI, catástrofes & $\begin{array}{l}\text { DS 509, 1983, Interior, aprueba } \\
\text { reglamento para la aplicación del } \\
\text { Decreto Ley No } 369 \text {, de } 1974 \text { (que } \\
\text { creó la ONEMI) }\end{array}$ & $\begin{array}{l}\text { 1. ONEMI } \\
\text { 2. Ministerio del Interior } \\
\text { 3. Intendente regional } \\
\text { 4. Comités regionales, provinciales y } \\
\text { comunales de emergencia }\end{array}$ \\
\hline $\begin{array}{l}\text { Parques y reservas } \\
\text { marinas }\end{array}$ & $\begin{array}{l}\text { DS 238, 2004, Economía, } \\
\text { Reglamento sobre Parques Marinos y } \\
\text { Reservas Marinas de la Ley General } \\
\text { de Pesca y Acuicultura }\end{array}$ & $\begin{array}{l}\text { 1. Ministerio de Economía } \\
\text { 2. Subsecretaría de Pesca } \\
\text { 3. SERNAPESCA } \\
\text { 4. DIRECTEMAR } \\
\text { 5. Ministerio de Defensa Nacional }\end{array}$ \\
\hline $\begin{array}{l}\text { Pequeña propiedad } \\
\text { raíz }\end{array}$ & $\begin{array}{l}\text { DL } 2.695 \text {, regularización de la } \\
\text { pequeña propiedad raíz }\end{array}$ & 1. Ministerio de Bienes Nacionales \\
\hline Pesca & $\begin{array}{l}\text { DL 2.442, establece funciones y } \\
\text { atribuciones del Ministerio de } \\
\text { Economía, Fomento y } \\
\text { Reconstrucción, en materia de } \\
\text { pesca; organiza la Subsecretaría de } \\
\text { Pesca; crea el Consejo Nacional de } \\
\text { Pesca y el Servicio Nacional de } \\
\text { Pesca }\end{array}$ & $\begin{array}{l}\text { 1. Ministerio de Economía } \\
\text { 2. Subsecretaría de Pesca, en } \\
\text { particular } \\
\text { 3. SERNAPESCA }\end{array}$ \\
\hline
\end{tabular}




\begin{tabular}{|c|c|c|}
\hline Materia & $\begin{array}{c}\text { Norma general de } \\
\text { ordenamiento territorial }\end{array}$ & Organismos regulados \\
\hline Pesca & $\begin{array}{l}\text { DFL 5, 1983, Economía, fija texto } \\
\text { refundido, coordinado y } \\
\text { sistematizado del Decreto con Fuerza } \\
\text { de Ley } 34 \text {, de 1931, que legisla sobre } \\
\text { la industria pesquera y sus derivados }\end{array}$ & $\begin{array}{l}\text { 1. Ministerio de Economía } \\
\text { 2. Subsecretaría de Pesca, en } \\
\text { particular } \\
\text { 3. SERNAPESCA }\end{array}$ \\
\hline Pesca & $\begin{array}{l}\text { DS } 240,1998, \text { Defensa, fija nómina } \\
\text { oficial de caletas de pescadores } \\
\text { artesanales }\end{array}$ & $\begin{array}{l}\text { 1. Subsecretaría de Marina } \\
\text { 2. DIRECTEMAR } \\
\text { 3. Dirección de Obras Portuarias } \\
\text { 4. SERNAPESCA }\end{array}$ \\
\hline Pesca y acuicultura & $\begin{array}{l}\text { DS 430, 1991, Economía, fija el } \\
\text { texto refundido, coordinado y } \\
\text { sistematizado de la Ley } N^{\circ} 18.892, \\
\text { de } 1989, \text { y sus modificaciones, Ley } \\
\text { General de Pesca y Acuicultura }\end{array}$ & $\begin{array}{l}\text { 1. Ministerio de Economía } \\
\text { 2. SERNAPESCA } \\
\text { 3. Subsecretaría de Pesca } \\
\text { 4. Ministerio de Defensa Nacional } \\
\text { 5. DIRECTEMAR } \\
\text { 6. Armada } \\
\text { 7. Carabineros } \\
\text { 8. Ministerio de Relaciones Exteriores }\end{array}$ \\
\hline Pesca y acuicultura & $\begin{array}{l}\text { DS 355, 1995, Economía, } \\
\text { Reglamento sobre Áreas de Manejo } \\
\text { y Explotación de Recursos } \\
\text { Bentónicos }\end{array}$ & $\begin{array}{l}\text { 1. Ministerio de Economía } \\
\text { 2. Subsecretaría de Pesca, en particular } \\
\text { 3. SERNAPESCA } \\
\text { 4. Ministerio de Defensa Nacional }\end{array}$ \\
\hline Pesca y acuicultura & $\begin{array}{l}\text { Ley } 20.091 \text {, modifica la ley general } \\
\text { de pesca y acuicultura en materia } \\
\text { de acuicultura, art. } 2^{\circ}\end{array}$ & $\begin{array}{l}\text { 1. Subsecretaría de Marina } \\
\text { 2. Subsecretaría de Pesca } \\
\text { 3. SERNAPESCA }\end{array}$ \\
\hline Piscinas & $\begin{array}{l}\text { DS 209, 2002, Salud, Reglamento } \\
\text { de Piscinas de Uso Público }\end{array}$ & $\begin{array}{l}\text { 1. SEREMI de Salud o Ministerio de } \\
\text { Salud (en cuanto sucesores del } \\
\text { Servicio Nacional de Salud) }\end{array}$ \\
\hline $\begin{array}{l}\text { Playa de mar, mar } \\
\text { territorial y franja de } \\
\text { derecho de uso de los } \\
\text { pescadores }\end{array}$ & $\begin{array}{l}\text { DFL } 1,2000, \text { Justicia, fija texto } \\
\text { refundido, coordinado y } \\
\text { sistematizado del Código Civil; de la } \\
\text { Ley } N^{\circ} 4.808 \text {, sobre registro civil; de } \\
\text { la Ley } N^{0} 17.344, \text { que autoriza } \\
\text { cambio de nombres y apellidos; de la } \\
\text { Ley } N^{0} 16.618, \text { Ley de Menores; de la } \\
\text { Ley } N^{\circ} 14.908 \text {, sobre abandono de } \\
\text { familia y pago de pensiones } \\
\text { alimenticias; y de la Ley } N^{\circ} 16.271 \text {, } \\
\text { de impuesto a las herencias, } \\
\text { asignaciones y donaciones }\end{array}$ & —__—_ \\
\hline Protección agrícola & $\begin{array}{l}\text { DL } 3.557 \text { establece disposiciones } \\
\text { sobre protección agrícola }\end{array}$ & 1. SAG \\
\hline Puertos & $\begin{array}{l}\text { Ley } 19.542, \text { moderniza el sector } \\
\text { portuario estatal }\end{array}$ & $\begin{array}{l}\text { 1. Empresas portuarias del Estado } \\
\text { 2. Ministerio de Transportes y } \\
\text { Telecomunicaciones }\end{array}$ \\
\hline $\begin{array}{l}\text { Reglamento General } \\
\text { de Orden, Seguridad y } \\
\text { Disciplina en las } \\
\text { Naves y Litoral de la } \\
\text { República (antiguo } \\
\text { Reglamento General }\end{array}$ & $\begin{array}{l}\text { DS } 1.340 \text { bis, } 1941 \text {, Defensa, } \\
\text { deroga el Decreto No } 211 \text {, de } 1924, \\
\text { que aprobó el Reglamento de } \\
\text { Policía Marítima y aprueba el } \\
\text { Reglamento General de Policía } \\
\text { Marítima, Fluvial y Lacustre }\end{array}$ & $\begin{array}{l}\text { 1. DIRECTEMAR o Autoridad } \\
\text { Marítima } \\
\text { 2. Servicio Nacional de Aduanas }\end{array}$ \\
\hline
\end{tabular}




\begin{tabular}{|c|c|c|}
\hline Materia & $\begin{array}{l}\text { Norma general de } \\
\text { ordenamiento territorial }\end{array}$ & Organismos regulados \\
\hline \multicolumn{3}{|l|}{$\begin{array}{l}\text { de Policía Marítima, } \\
\text { Fluvial y Lacustre) }\end{array}$} \\
\hline Ríos navegables & $\begin{array}{l}\text { DS } 12,1998 \text {, Defensa, fija nómina } \\
\text { oficial de ríos navegables por } \\
\text { buques de más de } 100 \text { toneladas }\end{array}$ & 1. DIRECTEMAR \\
\hline SAG & $\begin{array}{l}\text { Ley } 18.755 \text {, establece normas sobre } \\
\text { el Servicio Agrícola y Ganadero, } \\
\text { deroga la Ley } N^{\circ} 16.640 \text { y otras } \\
\text { disposiciones }\end{array}$ & $\begin{array}{l}\text { 1. SAG } \\
\text { 2. Carabineros } \\
\text { 3. Ministerio de Agricultura } \\
\text { 4. Ministerio de Hacienda }\end{array}$ \\
\hline Salud & $\begin{array}{l}\text { DFL 725, 1967, Salud, Código } \\
\text { Sanitario }\end{array}$ & $\begin{array}{l}\text { 1. Municipalidades } \\
\text { 2. Ministerio de Salud } \\
\text { 3. Ministerio del Interior }\end{array}$ \\
\hline SERNATUR & $\begin{array}{l}\text { DL } 1.224 \text {, crea el Servicio Nacional } \\
\text { de Turismo }\end{array}$ & 1. SERNATUR \\
\hline Servicios sanitarios & $\begin{array}{l}\text { DFL 382, 1988, Obras Públicas, Ley } \\
\text { General de Servicios Sanitarios }\end{array}$ & $\begin{array}{l}\text { 1. Superintendencia de Servicios } \\
\text { Sanitarios } \\
\text { 2. Municipalidad respectiva } \\
\text { 3. DGA } \\
\text { 4. Ministerio de Vivienda y Urbanismo } \\
\text { 5. Ministerio de Economía } \\
\text { 6. Ministerio de Obras Públicas } \\
\text { 7. Ministerio de Bienes Nacionales }\end{array}$ \\
\hline Servicios sanitarios & $\begin{array}{l}\text { Ley } 18.902, \text { crea la Superintendencia } \\
\text { de Servicios Sanitarios }\end{array}$ & $\begin{array}{l}\text { 1. Superintendencia de Servicios } \\
\text { Sanitarios }\end{array}$ \\
\hline SNASPE & $\begin{array}{l}\text { Ley } 18.362 \text {, crea un sistema } \\
\text { nacional de áreas silvestres } \\
\text { protegidas del Estado }\end{array}$ & $\begin{array}{l}\text { 1. CONAF } \\
\text { 2. Ministerio de Bienes Nacionales } \\
\text { 3. Ministerio de Agricultura } \\
\text { 4. Ministerio de Defensa Nacional } \\
\text { 5. Carabineros de Chile }\end{array}$ \\
\hline Sustancias peligrosas & $\begin{array}{l}\text { DS 298, 1994, Transportes, } \\
\text { reglamenta transporte de cargas } \\
\text { peligrosas por calles y caminos }\end{array}$ & $\begin{array}{l}\text { 1. Ministerio de Transportes y } \\
\text { Telecomunicaciones } \\
\text { 2. Carabineros de Chile } \\
\text { 3. Municipalidades }\end{array}$ \\
\hline Sustancias peligrosas & $\begin{array}{l}\text { DS } 148,2003, \text { Salud, Reglamento } \\
\text { Sanitario sobre Manejo de Residuos } \\
\text { Peligrosos }\end{array}$ & $\begin{array}{l}\text { 1. Autoridad Sanitaria } \\
\text { 2. Ministerio de Salud }\end{array}$ \\
\hline $\begin{array}{l}\text { Urbanismo y } \\
\text { construcciones }\end{array}$ & $\begin{array}{l}\text { DFL 458, 1975, Vivienda, nueva } \\
\text { Ley General de Urbanismo y } \\
\text { Construcciones }\end{array}$ & $\begin{array}{l}\text { 1. Ministerio de Vivienda y } \\
\text { Urbanismo } \\
\text { 2. Municipalidades (importancia } \\
\text { especial de la DOM y el asesor } \\
\text { urbanista, en su caso) } \\
\text { 3. Intendentes y Gobernadores }\end{array}$ \\
\hline $\begin{array}{l}\text { Urbanismo y } \\
\text { construcciones }\end{array}$ & $\begin{array}{l}\text { DS 47, 1992, Vivienda, fija nuevo } \\
\text { texto de la Ordenanza General de la } \\
\text { Ley General de Urbanismo y } \\
\text { Construcciones }\end{array}$ & $\begin{array}{l}\text { 1. Ministerio de Vivienda y } \\
\text { Urbanismo } \\
\text { 2. Municipalidades (importancia } \\
\text { especial de la DOM y el asesor } \\
\text { urbanista, en su caso) } \\
\text { 3. Intendentes y Gobernadores }\end{array}$ \\
\hline
\end{tabular}

Fuente: Guijón (2007). 


AGCI
CNUBC
CONAF
CONADI
CONAMA
COREMA
CRUBC
DOM
DDU
DFL O D.F.L.
DGA
DIRECTEMAR
DL O D.L.
DOP
DS O D.S.
FOSIS
MIDEPLAN
ONEMI
SAG
SEREMI
SERNAGEOMIN
SERNAPESCA
SERNATUR
SNASPE
SSM
SSP

Anexo $\mathrm{N}^{\circ} 2$

LISTA DE SIGLAS UTILIZADAS

Agencia de Cooperación Internacional de Chile Comisión Nacional de Uso del Borde Costero

Corporación Nacional Forestal

Corporación Nacional de Desarrollo Indígena

Comisión Nacional de Medio Ambiente

Comisión Regional de Medio Ambiente

Comisión Regional de Uso del Borde Costero

Departamento de Obras Municipales

Dirección de Desarrollo Urbano

Decreto con Fuerza de Ley

Dirección General de Aguas

Dirección de Territorio Marítimo y Marina Mercante

Decreto Ley

Dirección de Obras Portuarias

Decreto Supremo

Fondo de Solidaridad e Inversión Social

Ministerio de Planificación

Oficina Nacional de Emergencias

Servicio Agrícola y Ganadero

Secretaría Regional Ministerial

Servicio Nacional de Geología y Minería

Servicio Nacional de Pesca

Servicio Nacional de Turismo

Sistema Nacional de Áreas Silvestres Protegidas del Estado

Subsecretaría de Marina

Subsecretaría de Pesca 